\title{
Sample drying to improve HCHO measurements by PTR-MS instruments: laboratory and field measurements
}

\author{
B. T. Jobson and J. K. McCoskey \\ Laboratory for Atmospheric Research Department of Civil and Environmental Engineering, Washington State University, \\ Pullman, WA, USA
}

Received: 21 August 2009 - Published in Atmos. Chem. Phys. Discuss.: 23 September 2009

Revised: 31 December 2009 - Accepted: 13 January 2010 - Published: 17 February 2010

\begin{abstract}
A significant improvement in the PTR-MS instrument sensitivity to formaldehyde was obtained by drying the air sample to a dew point of $-30^{\circ} \mathrm{C}$ using a cold trap to condense and freeze water vapour. At warmer trap temperatures there was significant uptake of formaldehyde and other water soluble organics, suggesting the presence of a quasiliquid layer on the ice surface. By removing water vapour to a low constant dew point, the PTR-MS can be operated at low $E / N$ ratios, significantly increasing normalized sensitivities for all organics and removing their humidity dependence due to reactions with $\mathrm{H}^{+}\left(\mathrm{H}_{2} \mathrm{O}\right)_{2}$. At an $E / N$ ratio of $80 \mathrm{Td}$, the formaldehyde normalized sensitivity was $25 \mathrm{~Hz} / \mathrm{ppbv}$ per $\mathrm{MHz} \mathrm{H}_{3} \mathrm{O}^{+}$with an estimated detection limit of $78 \mathrm{pptv}$. Field testing demonstrated good agreement between $\mathrm{HCHO}$ measurements made at ambient humidity and corrected for water vapour effects compared to dehumidified sampling at $-30^{\circ} \mathrm{C}$. Field testing also revealed that at an $E / N$ ratio of $100 \mathrm{Td}$ or lower there was a significant ion signal at $\mathrm{m} / z=49$, likely $\mathrm{CH}_{3} \mathrm{OOH}$. Sampling drying and operation at low $E / N$ ratios enables sensitive measurements of $\mathrm{HCHO}$ and potentially $\mathrm{CH}_{3} \mathrm{OOH}$, both important tropospheric photoproducts.
\end{abstract}

\section{Introduction}

The proton transfer reaction mass spectrometer (PTR-MS) is a commercial instrument sold by Ionicon Analytik (Austria). Since its initial description (Hansel et al., 1995; Lindinger et al., 1998), it has found wide use in atmospheric chemistry field and laboratory studies for measuring trace organic

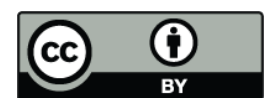

Correspondence to: $\mathrm{B}$. T. Jobson (tjobson@wsu.edu) gases. A description of its operating principle and performance can be found in the recent review article of deGouw and Warneke (2007). One advantage of this instrument over gas-chromatography based determinations of volatile organic compounds (VOCs) is the time resolution of the measurements and limited sample handling which makes determination of oxygenated species easier. However, formaldehyde has been proven difficult to measure with the PTR-MS. The sensitivity to formaldehyde is much less than other organics, due to a water vapour interference. The proton affinity of formaldehyde $(713 \mathrm{~kJ} / \mathrm{mol})$ is only slightly greater than that of water $(697 \mathrm{~kJ} / \mathrm{mol})$, so the exothermicity of the protonation Reaction (R1) is small. Within the drift tube, where the protonation reaction takes place, the kinetic energies of the reacting reagent ions are large enough that the endothermicity of the back Reaction (R2) can be overcome, and the rate of the back reaction can be significant (Hansel et al., 1997).

$$
\begin{aligned}
& \mathrm{HCHO}+\mathrm{H}_{3} \mathrm{O}^{+} \longrightarrow \mathrm{HCHOH}^{+}+\mathrm{H}_{2} \mathrm{O} \\
& \mathrm{HCHOH}^{+}+\mathrm{H}_{2} \mathrm{O} \longrightarrow \mathrm{HCHO}+\mathrm{H}_{3} \mathrm{O}^{+}
\end{aligned}
$$

The rate of the back reaction is dependent on the water vapor concentration, the electric field $E(\mathrm{~V} / \mathrm{cm})$, and the number density $N$ (molecules $/ \mathrm{cm}^{3}$ ) of the PTR-MS drift tube (Hansel et al., 1997). High drift pressures and low electric fields generally provide the best overall conditions to improve PTRMS sensitivity. For HCHO measurements, the adverse consequence of operating the PTR-MS at higher drift pressures is the corresponding increase in water vapour concentration in the drift tube which increases the rate of the back reaction. Operating at a lower electric field strength can reduce the back reaction rate constant but low ratios of $E / N$ cause excessive formation of water cluster ions (Reaction R3)

$\mathrm{H}_{3} \mathrm{O}^{+}+\mathrm{H}_{2} \mathrm{O} \longrightarrow \mathrm{H}^{+}\left(\mathrm{H}_{2} \mathrm{O}\right)_{2}$ 
The formation of water cluster ions complicates the determination of PTR-MS instrument sensitivities to VOCs because water clusters can also react with organics to produce protonated product ions. This can occur in 2 ways, by direct protonation of the organic by the water cluster ion (Reaction R4), or through ligand switching reactions (Reaction R5) and subsequent collision induced dissociation of the organic water cluster (Reaction R6)

$$
\begin{aligned}
& \mathrm{H}^{+}\left(\mathrm{H}_{2} \mathrm{O}\right)_{2}+\mathrm{R} \longrightarrow \mathrm{RH}^{+}+\left(\mathrm{H}_{2} \mathrm{O}\right)_{2}+ \\
& \mathrm{H}^{+}\left(\mathrm{H}_{2} \mathrm{O}\right)_{2}+\mathrm{R} \longrightarrow \mathrm{H}^{+}(\mathrm{R})\left(\mathrm{H}_{2} \mathrm{O}\right)+\mathrm{H}_{2} \mathrm{O} \\
& \mathrm{H}^{+}(\mathrm{R})\left(\mathrm{H}_{2} \mathrm{O}\right)+\mathrm{M} \longrightarrow \mathrm{RH}^{+}+\mathrm{H}_{2} \mathrm{O}+\mathrm{M}
\end{aligned}
$$

Species with proton affinities (PA) greater than the $808 \pm 6 \mathrm{~kJ} / \mathrm{mol}$ proton affinity of the water dimer (Goebbert and Wenthold, 2004 ; Midey et al., 2002) can be directly protonated. For species of atmospheric importance, these include isoprene $(\mathrm{PA}=826 \mathrm{~kJ} / \mathrm{mol})$, methyl vinyl ketone $(835 \mathrm{~kJ} / \mathrm{mol})$ styrene $(840 \mathrm{~kJ} / \mathrm{mol}), 1,3,5$-trimethylbenzene $(836 \mathrm{~kJ} / \mathrm{mol})$, and acetone $(812 \mathrm{~kJ} / \mathrm{mol})$ where the listed proton affinities were taken from Hunter and Lias (1998). Monoterpenes also appear to have PA's greater than the water dimer. The PA of $\alpha$-pinene and camphene was calculated to be $879 \mathrm{~kJ} / \mathrm{mol}$ by Solouki and Szulejko (2007), and the PA of limonene was measured to be $875 \pm 5 \mathrm{~kJ} / \mathrm{mol}$ by Fernandez et al. (1998). The ligand switching reactions are probably a more general mechanism for causing a water vapour dependent sensitivity (de Gouw and Warneke, 2007). Switching reactions are thought to be fast if exothermic and possibly need the organic molecule to have a significant dipole moment (Spanel and Smith, 1995). Midey et al. (2000) have measured the rate constants for formaldehyde and acetaldehyde reacting with $\mathrm{H}_{3} \mathrm{O}^{+}$and $\mathrm{H}^{+}\left(\mathrm{H}_{2} \mathrm{O}\right)_{2}$ using a SIFT. They observed that both species reacted with $\mathrm{H}^{+}\left(\mathrm{H}_{2} \mathrm{O}\right)_{2}$ in ligand switching reactions, with the $\mathrm{HCHO}+\mathrm{H}^{+}\left(\mathrm{H}_{2} \mathrm{O}\right)_{2}$ reaction rate being $75 \%$ of the calculated collision rate. This suggests that ligand switching reactions between $\mathrm{HCHO}$ and $\mathrm{H}^{+}\left(\mathrm{H}_{2} \mathrm{O}\right)_{2}$ could also occur in the drift tube of the PTR-MS.

Despite these complications, there are several reports of PTR-MS based measurements of $\mathrm{HCHO}$ which try to account for the humidity dependence of the sensitivity (Holzinger et al., 1999; Karl et al., 2003, 2007; Steinbacher et al., 2004; Inomata et al., 2008; Seco et al., 2008; Taipale et al., 2008). In this paper, we will show that the PTR-MS sensitivity to $\mathrm{HCHO}$ can be dramatically improved by removing water vapour from the sample stream. This has the advantages of decreasing the rate of the back reaction and keeping the water vapour concentration in the drift tube constant so that $\mathrm{HCHO}$ and other VOC sensitivities are independent of ambient water vapour concentration. Sample drying also has the added advantage of allowing the drift tube to be operated at much lower $E / N$ ratios. Reducing the ratio increases reaction times, further increasing sensitivities. The reduction in the $E / N$ ratio also reduces the degree of fragmentation from dissociative protonation reactions and may allow for the determination of $\mathrm{CH}_{3} \mathrm{OOH}$.

\section{Experimental}

\subsection{Impact of water vapour on HCHO normalized sensitivity}

Following Warneke et al. (2001), the normalized sensitivity is defined here as the $\mathrm{RH}^{+}$count rate per ppbv per $\mathrm{MHz}$ $\mathrm{H}_{3} \mathrm{O}^{+}$count rates $\left(1 \mathrm{ppbv}=1 \mathrm{nmol} \mathrm{mol}{ }^{-1}\right)$. This definition of sensitivity follows from the ion-molecule reaction kinetics in the drift tube where the $\mathrm{RH}^{+}$count rate is given as

$\mathrm{RH}^{+}=k t[R] \mathrm{H}_{3} \mathrm{O}^{+} \varepsilon$

with $k$ being the ion molecule rate coefficient, $t$ the reaction time, $[R]$ is the number density of the organic species in the drift tube, $\mathrm{RH}^{+}$and $\mathrm{H}_{3} \mathrm{O}^{+}$are the ion count rates $(\mathrm{Hz})$, and $\varepsilon$ is the ion transmission efficiency of $\mathrm{RH}^{+}$relative to $\mathrm{H}_{3} \mathrm{O}^{+}$. The reaction time is determined by the $\mathrm{H}_{3} \mathrm{O}^{+}$drift velocity and length of drift tube, so Eq. (1) can be re-written to account for the drift tube parameters on the reaction time:

$\mathrm{RH}^{+}=k\left(\frac{L N}{\mu_{o} N_{o} E}\right)[R] \mathrm{H}_{3} \mathrm{O}^{+} \varepsilon$

where $L$ is the drift length, $N$ is the number density of air in the drift tube, $N_{o}$ is the number density at $273 \mathrm{~K}$ and 1 atmosphere, $\mu_{o}$ is the reduced mobility of $\mathrm{H}_{3} \mathrm{O}^{+}$ $\left(2.76 \mathrm{~cm}^{2} \mathrm{~V}^{-1} \mathrm{~s}^{-1}\right)$, and $E$ is the electric field. Assuming $\varepsilon=1$, and a calculated thermal reaction rate coefficient of $2.0 \times 10^{-9} \mathrm{~cm}^{3}$ molecule ${ }^{-1} \mathrm{~s}^{-1}$ (Su and Chesnavich, 1982; $\mathrm{Su}, 1988$ ), a normalized sensitivity of $9.6 \mathrm{~Hz} / \mathrm{ppbv}$ can be calculated for benzene using the typical experimental conditions described in this paper: $120 \mathrm{Td}$ drift field intensity, $2.1 \mathrm{mbar}$ pressure, $50{ }^{\circ} \mathrm{C}$ drift temperature, $9.2 \mathrm{~cm}$ drift tube length. To increase the inherent sensitivity of the PTR-MS there are three strategies employed: increase the $\mathrm{H}_{3} \mathrm{O}^{+}$count rate, increase the concentration of the analyte by increasing the drift pressure, or increase the reaction time by decreasing the $E / N$ ratio. The ratio $E / N$ is given the unit of Townsends ( $\left.1 \mathrm{Td}=1 \times 10^{-17} \mathrm{~V} / \mathrm{cm}^{2}\right)$.

Figure 1 shows the impact of sample humidity on the reagent ion and first water cluster count rates, and the influence on normalized sensitivity for $\mathrm{HCHO}$, acetaldehyde and benzene for drift field intensities of 120 and $108 \mathrm{Td}$. The normalized sensitivities were determined from a 14 component VOC standard (Apel-Reimer Environmental) diluted to $19.8 \mathrm{ppbv}$ with humidified zero air. The diluent air was humidified to a range of water vapour concentrations by blending a dry zero air flow with a flow of humid zero air. Humid air was generated by passing zero air over purified water (deionized and filtered for organics). Air flows were metered with mass flow controllers and the resulting humidity of the 

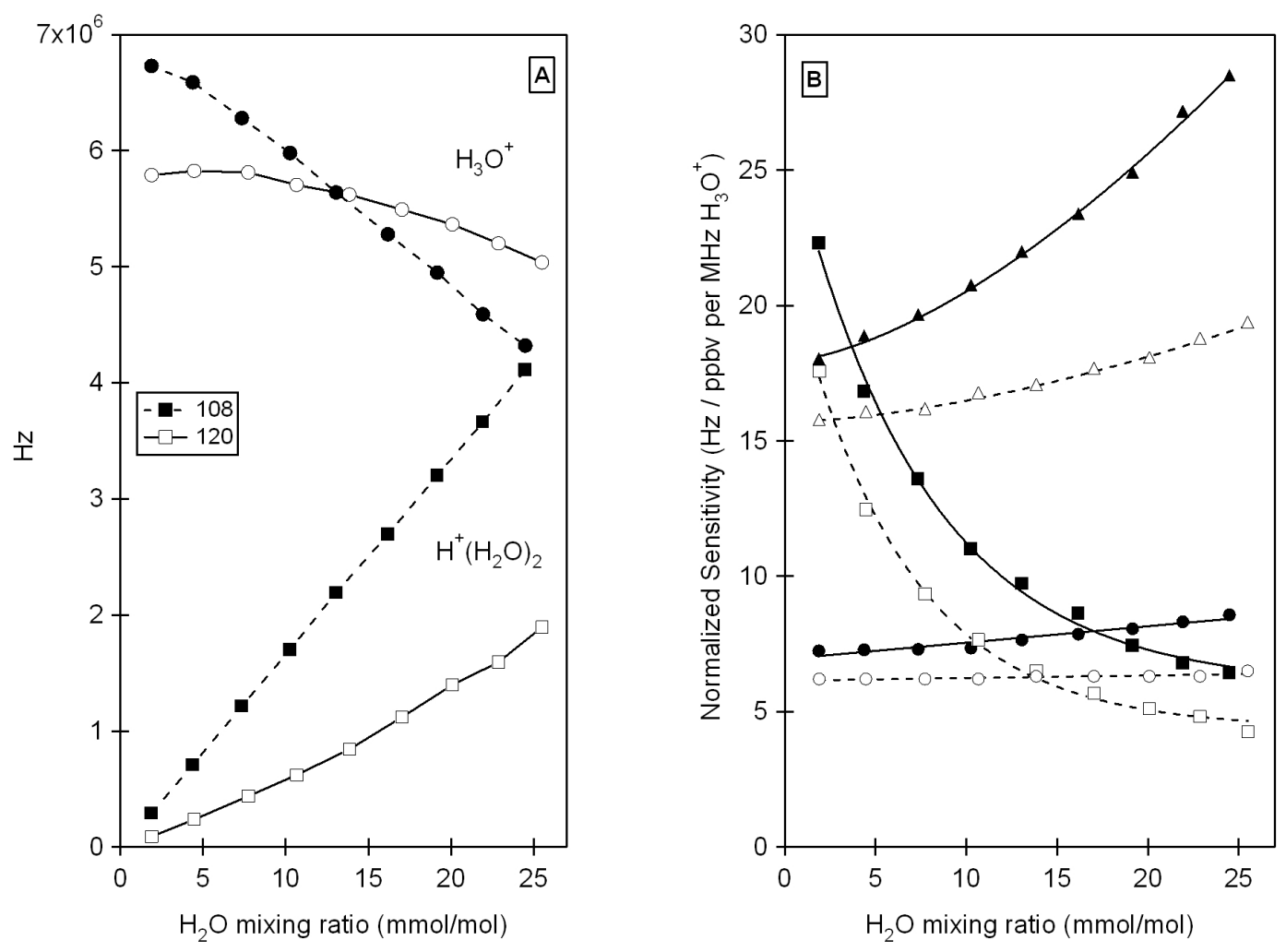

Fig. 1. Humidity dependence of ion count rates and normalized sensitivity for 120 and $108 \mathrm{Td}$ drift conditions at $2.1 \mathrm{mbar}$ pressure. The $\mathrm{Td}=120$ data are given by open symbols, $\mathrm{Td}=108$ data by filled symbols. Panel (A) count rates for $\mathrm{H}_{3} \mathrm{O}^{+}($circles $)$and $\mathrm{H}^{+}\left(\mathrm{H}_{2} \mathrm{O}\right)_{2}(\mathrm{squares})$. Panel (B) shows corresponding normalized sensitivity and fits to data for benzene (circles with linear fit), acetaldehyde (triangles with power law fit), and formaldehyde (squares with exponential fit).

diluent air measured by a relative humidity sensor (HumiCap, Vaisala). HCHO was added to this stream of air from a high emitting HCHO permeation source (KinTek, USA).

Figure 1 clearly shows the problem with $\mathrm{HCHO}$ measurements by PTR-MS. HCHO normalized sensitivities decreased exponentially with water vapour mixing ratios, decreasing by about a factor of 5 from dry conditions at $1.9 \mathrm{mmol} \mathrm{mol}^{-1}(0.19 \%)$ water vapour to humid conditions of $25 \mathrm{mmol} \mathrm{mol}^{-1}(2.5 \%)$ water vapour for the $120 \mathrm{Td}$ drift condition. A greater decrease was observed for the $108 \mathrm{Td}$ drift condition. In contrast to $\mathrm{HCHO}$, acetaldehyde normalized sensitivities increased with water vapour mixing ratios. If acetaldehyde was only protonated by reaction with $\mathrm{H}_{3} \mathrm{O}^{+}$the normalized sensitivity would not change. The increase implies that acetaldehyde was reacting with protonated water clusters such as $\mathrm{H}^{+}\left(\mathrm{H}_{2} \mathrm{O}\right)_{2}$. At the highest water vapour mixing ratios for the $108 \mathrm{Td}$ drift condition, the measured $\mathrm{H}^{+}\left(\mathrm{H}_{2} \mathrm{O}\right)_{2}$ signal was nearly equal to that of $\mathrm{H}_{3} \mathrm{O}^{+}$. Since the proton affinity of acetaldehyde is lower than that of the water dimer, the likely mechanism is ligand switching (Midey et al., 2000) and subsequent dissociation to produce protonated acetaldehyde. The normalized sensitivities of other polar organics tested but not shown in the figure, such as acetonitrile, acetone, 2-butanone and methacrolein, also displayed significant water vapour dependence. Benzene, on the other hand, displayed only a very weak increase in normalized sensitivity, increasing by only $4.4 \%$ at $\mathrm{Td}=120$ and $15.5 \%$ at $\mathrm{Td}=108$. Benzene does not have a permanent dipole moment and its ligand switching reaction rate has been measured to be very slow if it occurs at all (Spanel and Smith, 1995). The increase in benzene normalized sensitivity may be due to changes in the reaction time due to a decrease in $\mathrm{H}_{3} \mathrm{O}^{+}$mobility with higher water vapour concentration in the drift. At a lower $E / N$ ratio $(\sim \mathrm{Td}<100)$, Warneke et al. (2001) observed lower $\mathrm{H}_{3} \mathrm{O}^{+}$mobility with increasing humidity, but at higher $E / N$ ratios the humidity influence was not clear. Another explanation for our observed increase in benzene normalized sensitivity is the potential for loss of $\mathrm{H}_{3} \mathrm{O}^{+}$to clustering in the vacuum interface after the drift (Hanson et al., 2009). The observed benzene normalized sensitivity of $6.2 \mathrm{~Hz} / \mathrm{ppbv}$ at $120 \mathrm{Td}$ for dry conditions was $35 \%$ less than the sensitivity calculated from Eq. (2). At $108 \mathrm{Td}$ the difference was $31 \%$. In these experiments and in the field test described later, we used a ceramic based electron multiplier detector (ETP/SGE Analytical). 
Table 1. Percent difference in normalized sensitivities between dry air $\left(2 \mathrm{mmol} \mathrm{mol}^{-1}\right.$ water vapour $)$ and humid air $\left(>24 \mathrm{mmol} \mathrm{mol}^{-1}\right.$ water vapour).

\begin{tabular}{|c|c|c|c|c|c|}
\hline \multirow[t]{2}{*}{$m / z$} & \multirow[t]{2}{*}{ Species } & \multirow{2}{*}{$\begin{array}{l}\text { Proton } \\
\text { affinity } \\
(\mathrm{kJ} / \mathrm{mol})^{\mathrm{a}}\end{array}$} & \multirow{2}{*}{$\begin{array}{l}\text { Permanent } \\
\text { dipole } \\
\text { moment } \\
\text { (Debye) }^{b}\end{array}$} & \multicolumn{2}{|c|}{$\begin{array}{c}\% \text { Difference in } \\
\text { normalized sensitivity }\end{array}$} \\
\hline & & & & $\mathrm{Td}=120$ & $\mathrm{Td}=108$ \\
\hline 31 & formaldehyde & 712.9 & 2.18 & -75.6 & -246 \\
\hline 33 & methanol & 754.3 & 1.66 & 17.4 & 25.5 \\
\hline 42 & acetonitrile & 779.2 & 3.83 & 18.7 & 36.1 \\
\hline 45 & acetaldehyde & 786.5 & 2.65 & 23.6 & 36.8 \\
\hline 59 & acetone & 812 & 2.29 & 25.1 & 38.6 \\
\hline 69 & isoprene & 826.4 & 0.250 & 24.5 & 36.5 \\
\hline 71 & methacrolein & 808.7 & 2.80 & 22.8 & 37.9 \\
\hline 73 & 2-butanone & 827.3 & 2.76 & 30.2 & 45.4 \\
\hline 79 & benzene & 750.4 & 0.00 & 4.4 & 15.5 \\
\hline 93 & toluene & 784.0 & 0.343 & 11.2 & 28.9 \\
\hline 105 & styrene & 839.5 & 0.186 & 17.0 & 35.1 \\
\hline 107 & p-xylene & 794.4 & 0.081 & 19.3 & 35.3 \\
\hline 121 & 1,2,4-trimethylbenzene & & 0.291 & 18.3 & 36.0 \\
\hline 135 & 1,2,3,5-tetramethylbenzene & & & 14.9 & 37.3 \\
\hline 137 & $\alpha$-pinene & $879^{d}$ & 0.149 & 20.3 & 41.0 \\
\hline
\end{tabular}

${ }^{\text {a }}$ Hunter and Lias, 1998.

b Zhao and Zang, 2004.

c normalized sensitivity defined as $\mathrm{Hz} /$ ppbv per $\mathrm{MHz}_{3} \mathrm{O}^{+}$.

d Solouki and Szulejko, 2007.

Other aromatics examined, toluene, p-xylene, 1,2,4trimethylbenzne, styrene, and 1,2,3,5-tetramethylbenzene displayed a slightly stronger dependency on humidity than benzene. Midey et al. (2002) have observed proton transfer reactions between $\mathrm{H}^{+}\left(\mathrm{H}_{2} \mathrm{O}\right)_{2}$ and alkylbenzenes such as toluene in SIFT experiments. These reactions were fast, about half the collision rate, and were attributed to ligand switching reactions. It seems likely that toluene and the alkylbenzenes in our calibration mixture also undergo proton transfer reactions via ligand switching in the PTR-MS, resulting in the observed humidity dependent normalized sensitivities. Based on proton affinities, styrene could also be directly protonated by $\mathrm{H}^{+}\left(\mathrm{H}_{2} \mathrm{O}\right)_{2}$. Table 1 lists the percentage difference in VOC normalized sensitivity between the driest condition $\left(1.9 \mathrm{mmol} \mathrm{mol}^{-1}\right)$ and the most humid condition used in these experiments $\left(24.5 \mathrm{mmol} \mathrm{mol}^{-1}\right.$ at $\mathrm{Td}=108$ and 25.5 at $\mathrm{Td}=120$ ) together with corresponding proton affinities and permanent dipole moments. In all cases, except for formaldehyde, there was a significant increase in normalized sensitivity for the humid conditions.

The humidity dependent sensitivities for benzene and toluene have been examined in some detail by Warneke et al. (2001). In that study, conducted at 2.5 mbar drift pressure and a drift field intensity of $\sim 108 \mathrm{Td}$, the normalized sensitivity for benzene and toluene decreased nearly by a factor of 2 when the water vapour was decreased from
$5 \mathrm{mmol} \mathrm{mol}^{-1}$ to $27 \mathrm{mmol} \mathrm{mol}^{-1}$. Their results are in direct contrast to the results shown here. Warneke et al. (2001) explained their decrease in sensitivity to be a consequence of dissociation of $\mathrm{H}^{+}\left(\mathrm{H}_{2} \mathrm{O}\right)_{2}$ in the vacuum interface between the drift tube and quadrupole causing higher measured $\mathrm{H}_{3} \mathrm{O}^{+}$ than actually present in the drift tube. The higher drift pressure in that study resulted in a significantly greater relative abundance of $\mathrm{H}^{+}\left(\mathrm{H}_{2} \mathrm{O}\right)_{2}$ compared to $\mathrm{H}_{3} \mathrm{O}^{+}$. Steinbacher et al. (2004) also reported that benzene normalized sensitivity decreased by $16 \%$ over a similar humidity range. This suggests to us that the humidity dependence of benzene normalized sensitivity could be used as an instrument performance test to determine the fidelity of the ion sampling from the drift by the mass spectrometer interface. If benzene does not react with $\mathrm{H}^{+}\left(\mathrm{H}_{2} \mathrm{O}\right)_{2}$ in the PTR-MS, any change in its normalized sensitivity would indicate ion sampling artifacts. The caveat is the potential influence of water vapour on $\mathrm{H}_{3} \mathrm{O}^{+}$mobility. The expected normalized benzene sensitivity can also be readily calculated from the drift operating parameters, since benzene is only reacting with $\mathrm{H}_{3} \mathrm{O}^{+}$. The normalized sensitivity for benzene and its humidity dependence is probably the best metric for comparing different PTR-MS instruments and new designs sold by Ionicon Analytik. We note that different versions of the normalized sensitivity metric are used in the PTR-MS literature to account for various instrument factors that influence ion count 
rates per ppbv of analyte (de Gouw and Warneke, 2007; Taipale et al., 2008) but we prefer the simpler metric originally proposed by Warneke et al. (2001).

\subsection{Sample drying}

The technical approach to a water-removal system was based on cold trapping as is often done for VOC measurements by gas chromatography. The design of the dehumidifier was based on that used by Goldan et al. (1995). The dehumidifier assembly consisted of two $150 \mathrm{~mm} \times 6.4 \mathrm{~mm}$ OD stainless steel tubes coated with amorphous silicon (Silonite coating, Restek Inc.) mounted inside a block of aluminum that was cooled by an immersion cooler probe (FTP Systems). The tubes were in loose thermal contact with the block, with an air gap of $1.5 \mathrm{~mm}$ between the tube wall and the block. The immersion cooler probe cooled the block to about $-50^{\circ} \mathrm{C}$, cooling the tubes as well. The temperature of the tubes were controlled by resistive heating using a polyamide coated nichrome wire with a resistance of $\sim 95 \mathrm{ohms}$ (California Fine Wire Corp.) that was coiled around the tubes. The temperature of the individual tubes was controlled by temperature controllers (Watlow, USA) and tube temperature was monitored using an ungrounded thermocouple probe in contact with the inner tube wall. The thermocouple was inserted through a septum mounted on a Silonite coated tee on the upstream side of the tube. The tubes could, therefore, be held at a constant temperature ranging from the lower limit of the immersion cooler $\left(\sim-50^{\circ} \mathrm{C}\right)$ to an upper limit of about $100^{\circ} \mathrm{C}$. The tubes were thermally isolated from each other so that they could be operated independently; the temperature set-point of one did not impact the ability to control the temperature of the other. Water vapour was removed by pulling the sample air through a cold tube with the PTR-MS inlet flow. The water vapour condenses and freezes onto the tube surface, effectively lowering the dew point temperature of the sample air flow to that of the tube surface temperature.

The dehumidifier was constructed with two tubes to ensure continuous measurements over long time periods. Each tube of the dehumidifier was operated in one of three states: sample, condition and back flush. While one tube was removing water from the sample stream, the other tube was heated $\left(+70^{\circ} \mathrm{C}\right)$ and back flushed with dry nitrogen to remove ice accumulated in the tube during the last sample cycle. It was then cooled and conditioned with ambient air prior to sampling to ensure a seamless transition between tube measurement cycles. The conditioning state ensures that the VOC's have come to equilibrium with the ice-covered tube wall before being switched over to the sample state as described below. All flows through the tubes in the dehumidifier were directed by six 3-way PFA solenoid valves. The valves were arranged so that one tube can be in the sample mode, while the other tube can be operated in the back flush or conditioning state. While a tube is in the sample state, flow through the tube is determined by the PTR-MS inlet flow, set to approximately $250 \mathrm{ml} \mathrm{min}^{-1}$. Back flush and conditioning flows were regulated by two separate rotameters. Data acquisition and control of the dehumidifier apparatus was done using a LabJack U3-LV USB data acquisition device (LabJack, USA) and DaqFactory Standard software (Azeotech, USA). The LabJack U3-LV provided control voltages for all the valves and solenoids and inputs for digital and analog signals. DaqFactory provided the user interface and drivers to communicate with the LabJack U3-LV and temperature controllers. DaqFactory communicated with the temperature controllers through a serial 485 interface, allowing the high and low temperature set-points for each tube to be set by a software programme that automated functioning of the water trap.

The water trap efficiently removed water vapour from the sample at flow rates less than $300 \mathrm{ml} \mathrm{min}^{-1}$. This could be monitored by the PTR-MS by measuring the abundance of the water cluster ion $\mathrm{H}^{+}\left(\mathrm{H}_{2} \mathrm{O}\right)_{2}$. At flows greater than $300 \mathrm{ml} \mathrm{min}^{-1}$, the trap was less efficient as evidenced by an increase in $\mathrm{H}^{+}\left(\mathrm{H}_{2} \mathrm{O}\right)_{2}$ with air flow. The use of a cold tube to remove water by condensation could potentially also remove organics by physical adsorption to the cold surfaces. We conducted a series of experiments testing the transmission of $\mathrm{HCHO}$ and a suite of VOCs through the dehumidifier at different temperatures which are described below.

\subsection{Field test}

The water trap was field tested in the city of Houston, Texas as part of the Study of Houston Atmospheric Radical Precursor (SHARP) campaign from April-May 2009. The study was conducted on the roof of an 18-story building on the University of Houston campus. For the first two weeks of the campaign, the PTR-MS alternated between sampling through the water trap at $-30{ }^{\circ} \mathrm{C}$ and through PFA tubing at ambient room temperatures $\left(\sim 25{ }^{\circ} \mathrm{C}\right)$. The sampling duration was $25 \mathrm{~min}$ in each state. This allowed verification of potential losses of less volatile aromatic VOCs to the water trap and to verify the impact of ambient humidity on PTR-MS calibrations. Drift field intensity was $120 \mathrm{Td}$ with $2.1 \mathrm{mbar}$ drift pressure. After this test period, the PTR-MS sampled continuously through the water trap at $-30^{\circ} \mathrm{C}$ using drift field intensities of 120, 100 and $80 \mathrm{Td}$. The PTR-MS was calibrated and zeroed on an automated, regular schedule using a 14 VOC component compressed gas standard (ScottMarrin, USA). The standard was diluted to $19.8 \mathrm{ppbv}$ with humid zero air produced by scrubbing ambient air with a Pt catalyst $\left(1 \% \mathrm{Pt}\right.$ on alumina spheres) at $260^{\circ} \mathrm{C}$. $\mathrm{HCHO}$ was calibrated using a permeation tube with a stated permeation rate accuracy of $2 \%$. The permeation tube was placed in a permeation oven heated to $80^{\circ} \mathrm{C}$ and the permeation flow $\left(100 \mathrm{ml} \mathrm{min}^{-1}\right.$ zero grade air) added to the diluted multicomponent standard flow to yield $43 \mathrm{ppbv} \mathrm{HCHO}$. The permeation oven was not as well thermostated as we would have liked and observed that its temperature varied $\pm 2{ }^{\circ} \mathrm{C}$ as room 


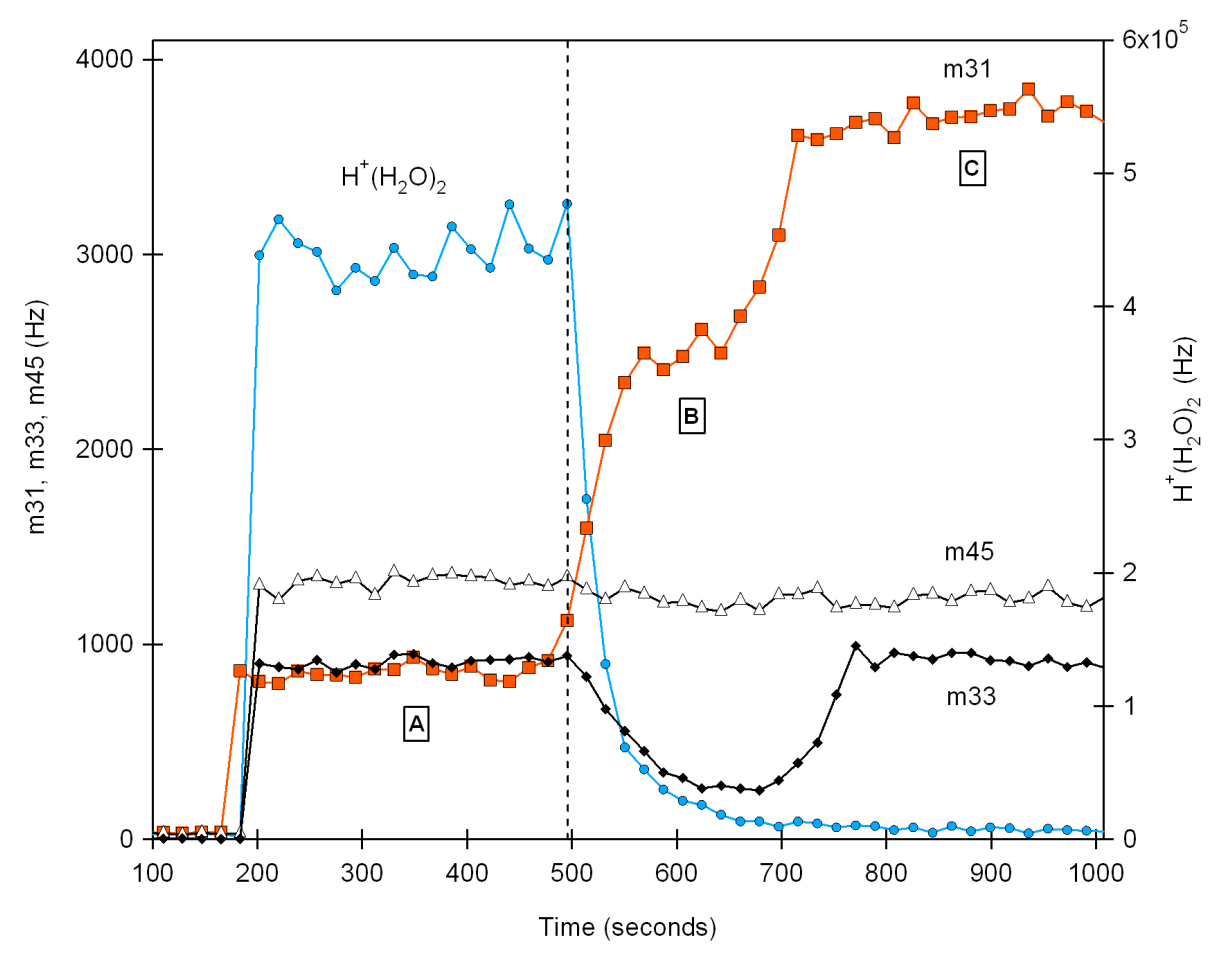

Fig. 2. Impact of water trap on formaldehyde (m31), methanol (m33), and acetaldehyde (m45) ion signals. PTR-MS switches from sampling at $50 \% \mathrm{RH}$ at $23^{\circ} \mathrm{C}$ (region A) at about the $500 \mathrm{~s}$ mark to sampling through the water trap at $-40{ }^{\circ} \mathrm{C}$ as indicated by dashed line and abrupt decrease in $\mathrm{H}^{+}\left(\mathrm{H}_{2} \mathrm{O}\right)_{2}$ count rates. Formaldehyde initially increases to a level indicated by region B as trap accumulates ice and PTR-MS dries (conditioning period), then increases to a final value indicated by region $\mathrm{C}$. By contrast, methanol decreases then recovers to original count rate.

temperature varied. The automated calibrations and zeroes were performed for both the dehumidified and ambient humidity sampling.

\section{Results}

\subsection{Trap conditioning}

Tests were performed to determine the optimum temperature and flow rates for operating the trap. The lower the water trap temperature, the more water vapour is removed improving sensitivity to $\mathrm{HCHO}$. The concern with the trap was that $\mathrm{HCHO}$ would be lost to the ice accumulating in the water trap and that other VOCs, such as larger aromatics with lower vapour pressures, would also be removed to the cold ice surface.

Figure 2 illustrates the impact of the dehumidifier on a $19.8 \mathrm{ppbv}$ calibration mixture at a relative humidity of $50 \%$ at $23^{\circ} \mathrm{C}$. There are three identifiable ion signal regions that we labelled A, B, and C. Region A is the ion signal at an ambient tube temperature $\left(23^{\circ} \mathrm{C}\right)$ corresponding to normal air sampling to serve as a reference point to compare with dehumidified sampling. In region $\mathrm{A}$, water vapour in the sample contributes to a decrease in $\mathrm{HCHO}$ sensitivity and a lower observed count rate. The sample was then redirected by solenoid valves through the water trap at a temperature of $-40^{\circ} \mathrm{C}$. Region B was identified as a conditioning period as the tube becomes coated with ice and adsorbed VOCs. During this period, there was a significant decrease in the methanol ion signal as it is lost to the cold tube. In contrast, the HCHO ion signal increased, due to the reduction of water vapour in the drift tube. After $\sim 7 \mathrm{~min}$, the $\mathrm{HCHO}$ signal was reasonably stable at $\sim 3800 \mathrm{~Hz}$. At this point, the HCHO was in equilibrium with the cold ice surface, identified as region $\mathrm{C}$. In region $\mathrm{C}$, the methanol ion signal has recovered to values similar to region $\mathrm{A}$. The sample drying is illustrated by the large change in $\mathrm{H}^{+}\left(\mathrm{H}_{2} \mathrm{O}\right)_{2}$ count rates, from $\sim 450,000 \mathrm{~Hz}$ at room temperature to $\sim 3800 \mathrm{~Hz}$ at $-40^{\circ} \mathrm{C}$. Removing water vapour by condensing it in a cold tube clearly improved the PTR-MS sensitivity to HCHO. The $\mathrm{HCHO}$ ion count rate at $-40^{\circ} \mathrm{C}$ was 5 times greater than at $23^{\circ} \mathrm{C}$.

Figure 2 also highlights a clear need for a conditioning period in which the tube becomes passivated before efficient transmission through the water trap is possible. This practice of conditioning is part of the general lore of VOC analysis, though not well quantified nor illustrated in the literature. We conducted several tests using dry and humidified test mixtures to determine losses of VOCs to cold tubing. 


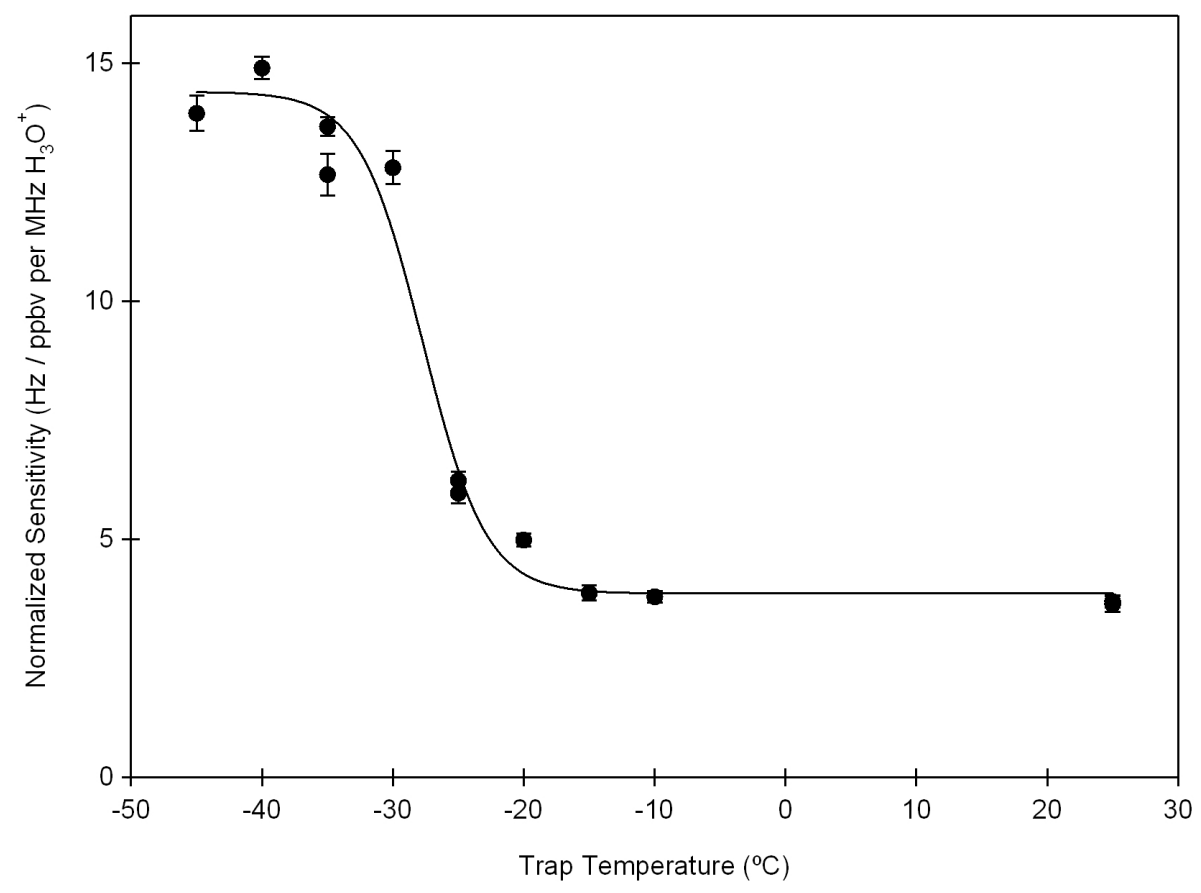

Fig. 3. Dependence of $\mathrm{HCHO}$ normalized sensitivity on water trap temperature for $50 \% \mathrm{RH}$ sample flow at $23{ }^{\circ} \mathrm{C}$. PTR-MS conditions were $120 \mathrm{Td}, 2.4 \mathrm{mbar}$ pressure, $50^{\circ} \mathrm{C}$ drift temperature. Trace is a sigmoid fit through the data to illustrate the abrupt increase in sensitivity at water trap temperatures below $-25^{\circ} \mathrm{C}$.

Even for relatively volatile species a conditioning effect was observed. For example, tests with our $\mathrm{HCHO}+$ multicomponent VOC test mixture in dry air showed that $\sim 10 \mathrm{ng}$ of $\mathrm{HCHO}$ adsorbed to the Silonite coated steel tubing at $-65^{\circ} \mathrm{C}$ before the tube was passivated and allowed $100 \%$ transmission of HCHO. Higher mass flows led to quicker conditioning times. Conditioning is a complex surface adsorption process dependent on the nature of the sample including the VOC composition and abundance and the amount of water vapour. For the water trap, the tubes become coated with ice so the interaction of the VOC with ice becomes an important process. For the less volatile non-polar aromatic compounds in our test mixture, 1,2,3,5-tetramethlybenzene and 1,2,4-trimethylbenzene, lower tube temperatures lead to greater losses as would be anticipated from surface losses due to physical adsoprtion. Interestingly, for water soluble species such as HCHO and methanol, colder trap temperatures lead to greater transmission efficiencies.

\subsection{Loss of water soluble species to warm ice}

We observed that the improvement in $\mathrm{HCHO}$ sensitivity was a nonlinear function of the trap temperature. Figure 3 shows a plot of $\mathrm{HCHO}$ normalized sensitivity versus water trap temperature for a series of tests conducted at $2.4 \mathrm{mbar}$ drift pressure and $\mathrm{Td}=120$ drift field intensity. We found a steep increase in $\mathrm{HCHO}$ sensitivity at temperatures lower than $-25^{\circ} \mathrm{C}$. There appears to be a transition at this temperature.
We believe this transition is due to soluble VOCs being taken up into a liquid-like layer on the ice surface at temperatures greater than $-25^{\circ} \mathrm{C}$ (Dash et al., 1995). This transition is clearly seen in Fig. 4. The figure shows results from a test comparing the transmission of a $19.8 \mathrm{ppbv}$ cal mixture through the water trap at -30 and $-25^{\circ} \mathrm{C}$. The bottom panel shows the $\mathrm{H}^{+}\left(\mathrm{H}_{2} \mathrm{O}\right)_{2}$ ion count rates. Initially the PTR-MS samples dry zero air, then the calibration mixture at $50 \% \mathrm{RH}$ through the tube at $23^{\circ} \mathrm{C}$, then the sample passes through the water trap. The cycle was then repeated for the other water trap temperature. Passage through the water trap is indicated by the drop in the water cluster count rates. It can be seen that there was no significant change in the aromatic count rates (benzene, 1,2,4-trimethylbenzene) as the sample was switched from a tube at $+25^{\circ} \mathrm{C}$ to $-30^{\circ} \mathrm{C}$. There was, however, a dip in the methanol count rates which then recovered to those observed for the $+25^{\circ} \mathrm{C}$ condition. Similarly, there was a small dip in the acetonitrile count rates which then recovered. HCHO count rates initially increased (due to lower water vapour concentration), levelled out for $\sim 300 \mathrm{~s}$, and then increased to a plateau. A much different behaviour was observed for the trap temperature of $-25^{\circ} \mathrm{C}$. While the aromatics passed through unaffected, methanol and acetonitrile were persistently lower, indicating continual loss to the trap; the trap never conditioned. HCHO count rates increased initially then slowly decreased. This behaviour is consistent with uptake into a liquid water 

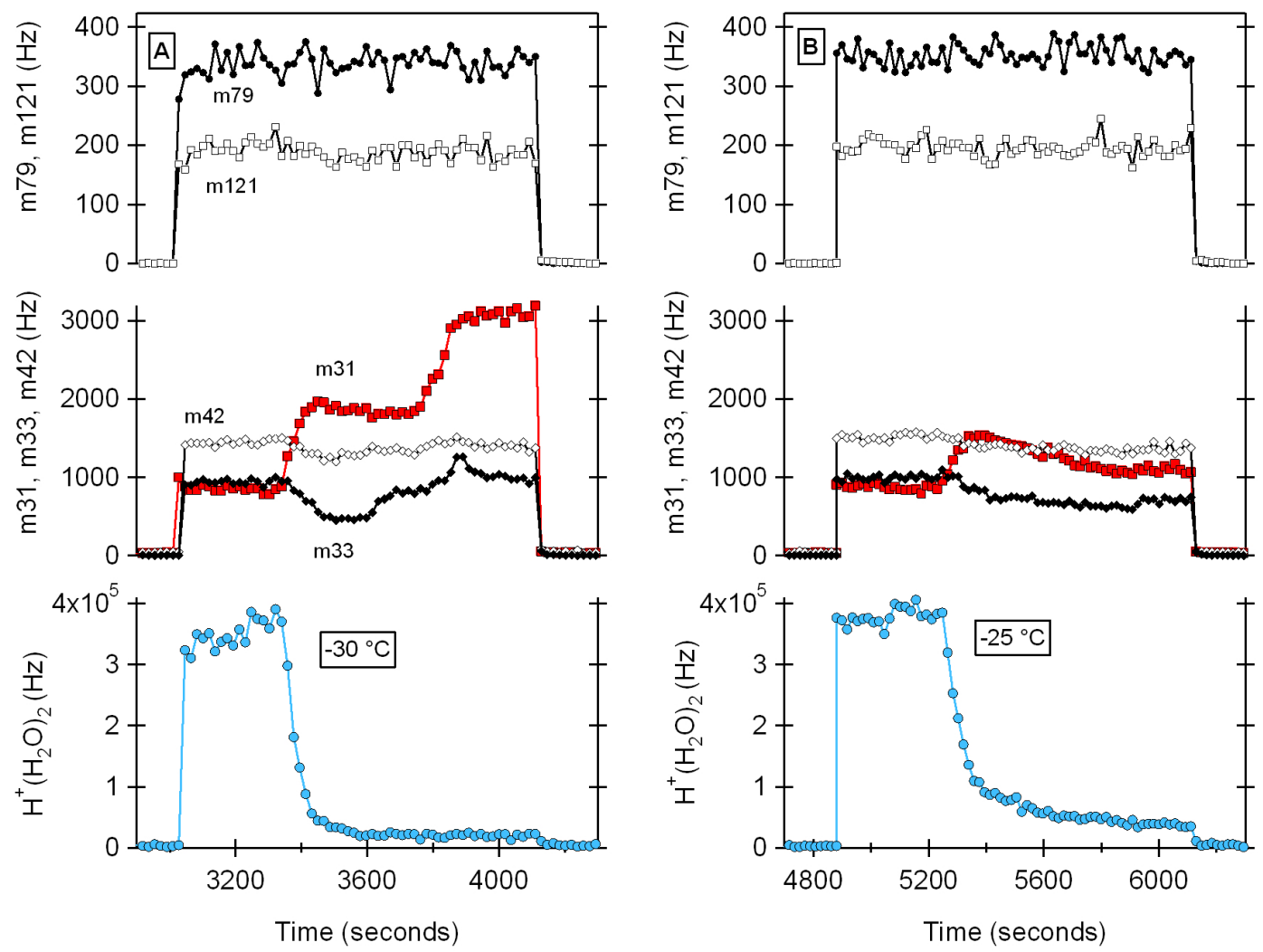

Fig. 4. Illustration of HCHO (m31), methanol (m33), and acetonitrile (m42) loss to warm ice. Panel (A) shows change in ion signal as PTR-MS switches from sampling at $50 \% \mathrm{RH}$ at $23^{\circ} \mathrm{C}$ to sampling through water trap at $-30{ }^{\circ} \mathrm{C}$. An abrupt decrease in the $\mathrm{H}^{+}\left(\mathrm{H}_{2} \mathrm{O}\right)_{2}$ ion signal indicates when the PTR-MS samples through the water trap. Methanol displayed an initial decrease in ion signal then recovered to the ambient RH level. Panel (B) shows the change in ion signal for sampling through $\mathrm{a}-25^{\circ} \mathrm{C}$ water trap temperature. In this case, the methanol and acetonitrile count rates did not recover to those observed for ambient RH sampling. HCHO initially increased then decreased to a count rate slightly greater than ambient RH conditions. Benzene (m79) and 1,2,4-trimethylbenzene (m121) displayed no losses to water trap at either temperature.

surface that is constantly being replenished. Formaldehyde is very soluble with a Henry's law coefficient at $-25^{\circ} \mathrm{C}$ of $3.1 \times 10^{5} \mathrm{M} \mathrm{atm}^{-1}$ (Staudinger and Roberts, 1996). Partitioning into the liquid water layer would qualitatively explain loss of formaldehyde from the sample flow. At a trap temperature of $-25^{\circ} \mathrm{C}$, less formaldehyde makes it through the tube than the ambient $\mathrm{RH}$ condition, despite the lower water vapour concentration in the drift tube and the inherently greater normalized sensitivity. This absorption effect was also observed for methanol but not for other gases in the test mixture such as acetaldehyde, acetone, and methacrolein. At $-25^{\circ} \mathrm{C}$ these species have a Henry's Law coefficient of at least a factor of 9 less than that of methanol and partitioning into the liquid phase would not be as significant, consistent with our observations. Thus, two effects determine the transmission efficiency through the water trap: physical adsorption of VOC's to ice or the tubing surface and absorption of soluble VOC's into a quasi liquid layer of water on the ice surface. From these tests we concluded that the optimum trap temperature was $-30^{\circ} \mathrm{C}$. At trap temperatures colder than this, we observed losses of 1,2,3,5-tetramethylbenzene. At trap temperatures warmer than this, there were significant losses of soluble species such as methanol. A conditioning flow rate of $200-300 \mathrm{ml} \mathrm{min}^{-1}$ for $6 \mathrm{~min}$ was adequate for conditioning the trap for $\mathrm{HCHO}$ and other VOCs.

\subsection{Field calibrations}

Figure 5 shows the normalized sensitivities for $\mathrm{HCHO}$, benzene, acetaldehyde, isoprene and acetonitrile as a function of the normalized water cluster count rates for the ambient humidity calibrations. The relative humidity of the sample air was measured with a sensor and was well correlated with $\mathrm{H}^{+}\left(\mathrm{H}_{2} \mathrm{O}\right)_{2}$ count rates. $\mathrm{HCHO}$ normalized sensitivity displayed an exponential dependence on the water cluster count rates. At the highest water cluster count rates, corresponding to a dew point of $22^{\circ} \mathrm{C}$, the normalized sensitivity for $\mathrm{HCHO}$ was $2.7 \mathrm{~Hz} / \mathrm{ppbv}$. At the lowest water cluster count rates, corresponding to a dew point of $1^{\circ} \mathrm{C}$, the normalized sensitivity was $5.9 \mathrm{~Hz} / \mathrm{ppbv}$. Most VOC species displayed a 
Table 2. Averaged normalized sensitivities ( $\mathrm{Hz} / \mathrm{ppbv}$ per $\mathrm{MHz}_{3} \mathrm{O}^{+}$).

\begin{tabular}{llrrrr}
\hline$m / z$ & Species & $\begin{array}{r}\text { Ambient } \\
\mathrm{RH}\end{array}$ & \multicolumn{2}{c}{ Dehumidified at $-30^{\circ} \mathrm{C}$} \\
\cline { 3 - 5 } & & $\mathrm{Td}=120$ & $\mathrm{Td}=120$ & $\mathrm{Td}=100$ & $\mathrm{Td}=80$ \\
\hline 31 & formaldehyde & $3.4 \pm 0.8$ & $11.3 \pm 1.1$ & $16.9 \pm 1.1$ & $25.0 \pm 1.5$ \\
33 & methanol & $10.5 \pm 0.6$ & $10.4 \pm 0.6$ & $13.4 \pm 0.5$ & $19.1 \pm 1.2$ \\
42 & acetonitrile & $17.9 \pm 1.1$ & $17.3 \pm 0.6$ & $23.7 \pm 0.3$ & $35.4 \pm 0.7$ \\
45 & acetaldehyde & $14.2 \pm 0.9$ & $13.5 \pm 0.5$ & $18.5 \pm 0.2$ & $26.4 \pm 0.4$ \\
59 & acetone & $15.2 \pm 0.9$ & $14.6 \pm 0.5$ & $19.9 \pm 0.5$ & $29.7 \pm 0.6$ \\
69 & isoprene & $10.0 \pm 0.6$ & $9.5 \pm 0.5$ & $14.0 \pm 0.3$ & $20.3 \pm 0.4$ \\
71 & methacrolein & $8.6 \pm 0.5$ & $8.1 \pm 0.4$ & $11.9 \pm 0.3$ & $17.6 \pm 0.3$ \\
73 & 2-butanone & $19.1 \pm 1.1$ & $18.5 \pm 0.7$ & $25.5 \pm 0.6$ & $37.8 \pm 0.7$ \\
79 & benzene & $9.7 \pm 0.4$ & $10.2 \pm 0.6$ & $13.3 \pm 0.3$ & $18.4 \pm 0.3$ \\
93 & toluene & $10.0 \pm 0.5$ & $10.1 \pm 0.5$ & $13.2 \pm 0.3$ & $18.5 \pm 0.3$ \\
105 & styrene & $10.5 \pm 0.5$ & $10.6 \pm 0.6$ & $13.6 \pm 0.4$ & $19.4 \pm 0.3$ \\
107 & p-xylene & $9.2 \pm 0.5$ & $9.2 \pm 0.4$ & $11.8 \pm 0.3$ & $17.1 \pm 0.3$ \\
121 & 1,2,4-trimethylbenzene & $8.5 \pm 0.5$ & $8.6 \pm 0.5$ & $10.8 \pm 0.4$ & $15.7 \pm 0.3$ \\
135 & 1,2,3,5-tetramethylbenzene & $8.1 \pm 0.8$ & $8.0 \pm 0.7$ & $9.5 \pm 0.4$ & $13.7 \pm 0.3$ \\
137 & $\alpha$-pinene & $3.2 \pm 0.2$ & $3.1 \pm 0.2$ & $4.5 \pm 0.2$ & $7.5 \pm 0.2$ \\
\hline
\end{tabular}
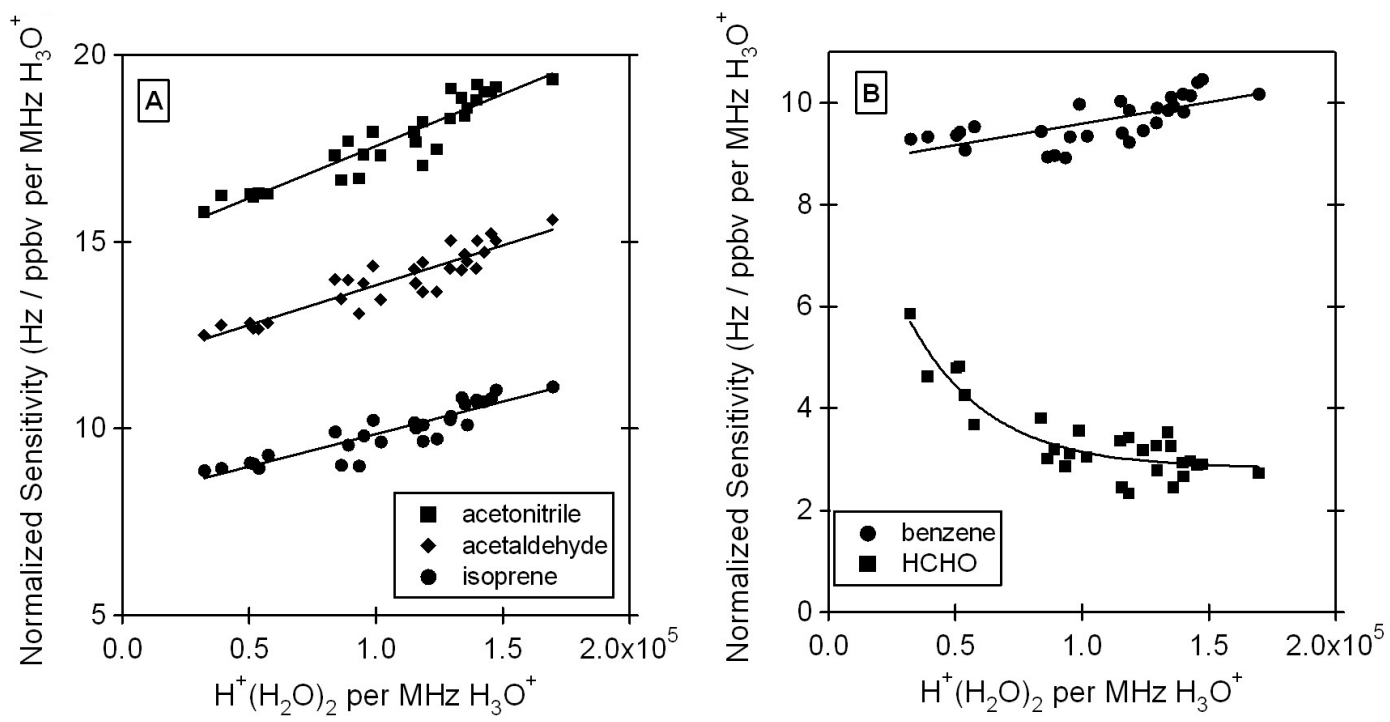

Fig. 5. Dependence of normalized sensitivities on water cluster count rates. Water cluster count rates were normalized to $\mathrm{MHz}_{\mathrm{H}}$ of $\mathrm{H}_{3} \mathrm{O}^{+}$. Panel (A) shows acetontrile, acetaldehyde and isoprene as examples of the positive linear dependence most species displayed. Panel (B) illustrates a weaker dependence for benzene and a negative exponential dependence for HCHO.

positive linear dependence on the cluster count rates, indicating humidity dependent sensitivities likely due to reactions with $\mathrm{H}^{+}\left(\mathrm{H}_{2} \mathrm{O}\right)_{2}$. Benzene displayed the weakest dependence as expected, since it is not thought to react with the water dimer. The fits to these calibrations were used together with measured water cluster count rates to determine mixing ratios from the ambient ion signals. The averaged normalized sensitivities for ambient humidity calibrations compared to the dehumidified calibrations are shown in Table 2. On average, reducing water vapour concentration to $-30^{\circ} \mathrm{C}$ dew point increased the $\mathrm{HCHO}$ normalized sensitivity by a factor of 3 .

For the dehumidified calibrations, the average normalized water cluster count rates were $4700 \pm 800$. It is noted from Table 2 that the dehumidified calibration values were consistently and significantly greater than the trend line extrapolation to low humidity in Fig. 5. The reason for the higher than expected sensitivities is that $\mathrm{H}_{3} \mathrm{O}^{+}$count rates were consistently lower in the dehumidified mode. On average, 


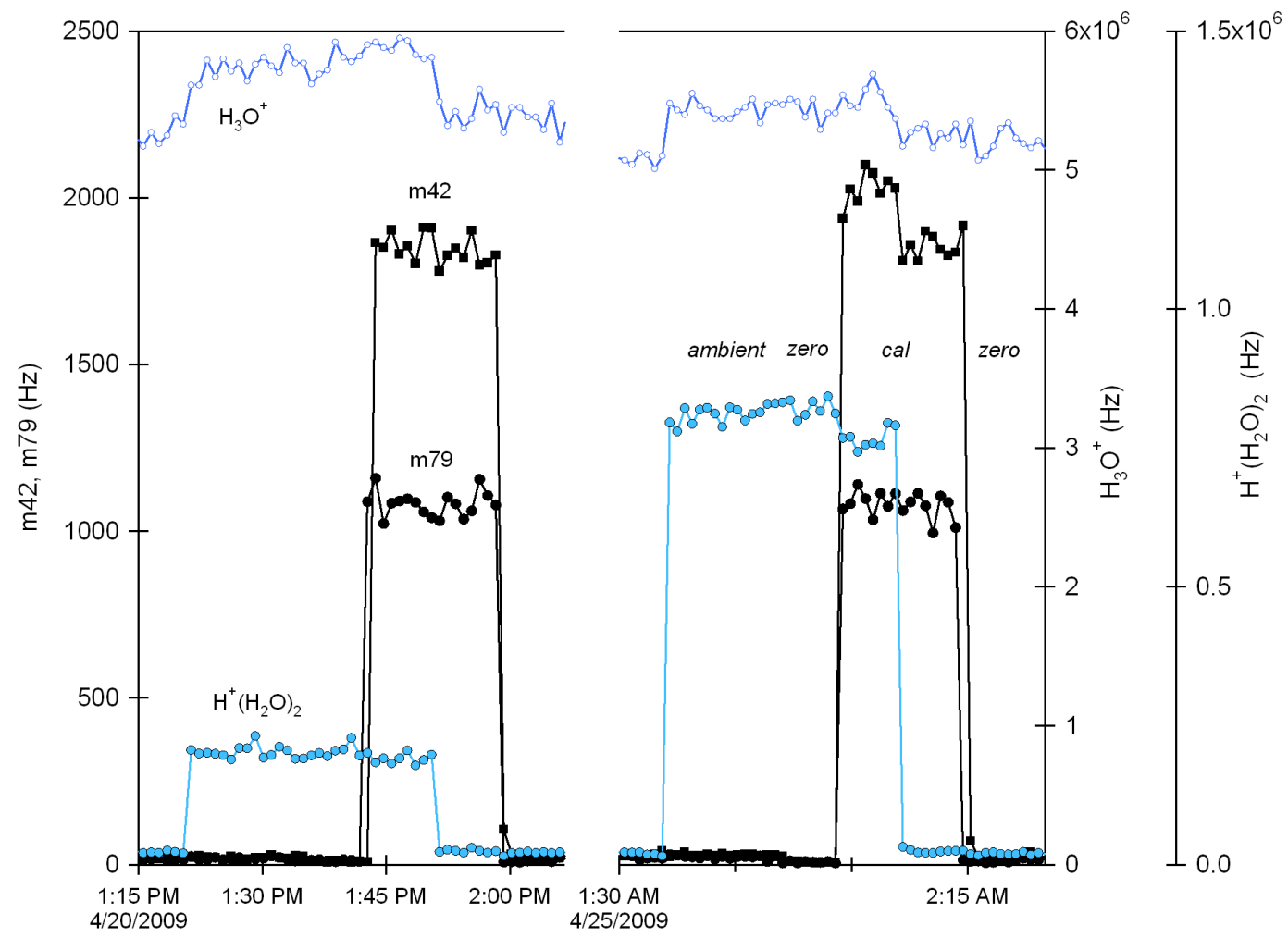

Fig. 6. Acetonitrile (m42, squares), benzene (m79, circles), $\mathrm{H}_{3} \mathrm{O}^{+}$(open blue circles) and $\mathrm{H}^{+}\left(\mathrm{H}_{2} \mathrm{O}\right)_{2}$ (filled blue circles) ion signals during calibration. Shown, are two different days representing relatively dry (20 April) and humid (25 April) sampling conditions. For both time periods the data show a sequence of ambient air sampling (ambient), followed by zero air sampling (zero), addition of calibration gases (cal) and a final zero air period. The decrease in $\mathrm{H}^{+}\left(\mathrm{H}_{2} \mathrm{O}\right)_{2}$ signal during calibration was due to the addition of dry calibration gas to the humid zero air flow. Sampling through the water trap is apparent by the decrease in $\mathrm{H}^{+}\left(\mathrm{H}_{2} \mathrm{O}\right)_{2}$ count rates. A significant decrease in $\mathrm{H}_{3} \mathrm{O}^{+}$was always observed when sampling through the water trap.

the $\mathrm{H}_{3} \mathrm{O}^{+}$count rates were $6.7 \pm 2.3 \%$ less when sampling through the water trap during calibration periods. For many VOCs there was little difference in the ion signal during calibration between ambient $\mathrm{RH}$ and dehumidified sampling for dry conditions. This is shown in Fig. 6 where 2 field calibration periods are depicted: 20 April representing relatively dry conditions and 25 April representing relative humid conditions as indicated by the $\mathrm{H}^{+}\left(\mathrm{H}_{2} \mathrm{O}\right)_{2}$ count rates. For benzene $(m / z=79)$, there was no discernable change in ion signals when the PTR-MS sampled through the water trap for either calibration period. However, the decrease in $\mathrm{H}_{3} \mathrm{O}^{+}$count rates when sampling through the water trap, $-7.6 \%$ for the 20 April calibration and $-4.3 \%$ for the 25 April calibration, causes the normalized sensitivity to be greater for dehumidified sampling. For acetonitrile $(m / z=42)$, there was no significant difference in ion signals between ambient humidity and water trap calibration for the April 20 period, thus, the dehumidified normalized sensitivity is $7.6 \%$ larger because of the difference in $\mathrm{H}_{3} \mathrm{O}^{+}$count rates. For 25 April, the ambient humidity calibration displayed a significantly higher count rate than on 20 April and a significant drop in the count rate through the water trap. During this period, the $\mathrm{H}^{+}\left(\mathrm{H}_{2} \mathrm{O}\right)_{2}$ ion count rate was $15 \%$ of the $\mathrm{H}_{3} \mathrm{O}^{+}$count rate compared to $3.4 \%$ for the 20 April ambient humidity calibration. The difference in acetontrile behaviour between the 2 calibration periods is qualitatively consistent with $\mathrm{H}^{+}\left(\mathrm{H}_{2} \mathrm{O}\right)_{2}$ acting a reagent ion. It was clear from the calibrations that the PTRMS sensitivity in dehumidified mode could not be extrapolated from the ambient humidity trend lines given in Fig. 5.

Figure 7 illustrates the impact of the water trap on $\mathrm{H}^{+}\left(\mathrm{H}_{2} \mathrm{O}\right)_{2}$ and formaldehyde $(\mathrm{m} / \mathrm{z}=31)$ count rates. When the trap switched to sampling through the $-30^{\circ} \mathrm{C}$ water trap, count rates for $\mathrm{H}^{+}\left(\mathrm{H}_{2} \mathrm{O}\right)_{2}$ decreased to $\sim 21000 \mathrm{~Hz}$, while count rates for formaldehyde increased, producing a crenulated pattern. The HCHO mixing ratio could be determined from the $m / z=31$ count rate by applying the respective humidity dependent normalized sensitivity for the ambient humidity data, and the $11.3 \mathrm{~Hz} / \mathrm{ppbv}$ sensitivity factor for the data collected at $-30^{\circ} \mathrm{C}$. Count rates for $\mathrm{H}_{3} \mathrm{O}^{+}$were reasonably steady at $5 \times 10^{6} \mathrm{~Hz}$ during the entire field campaign. The resulting $\mathrm{HCHO}$ mixing ratios from the 2 sampling conditions were well matched, indicating the humidity dependent sensitivity was accounted for correctly and there were no significant losses of HCHO to the water trap. It is apparent in the 

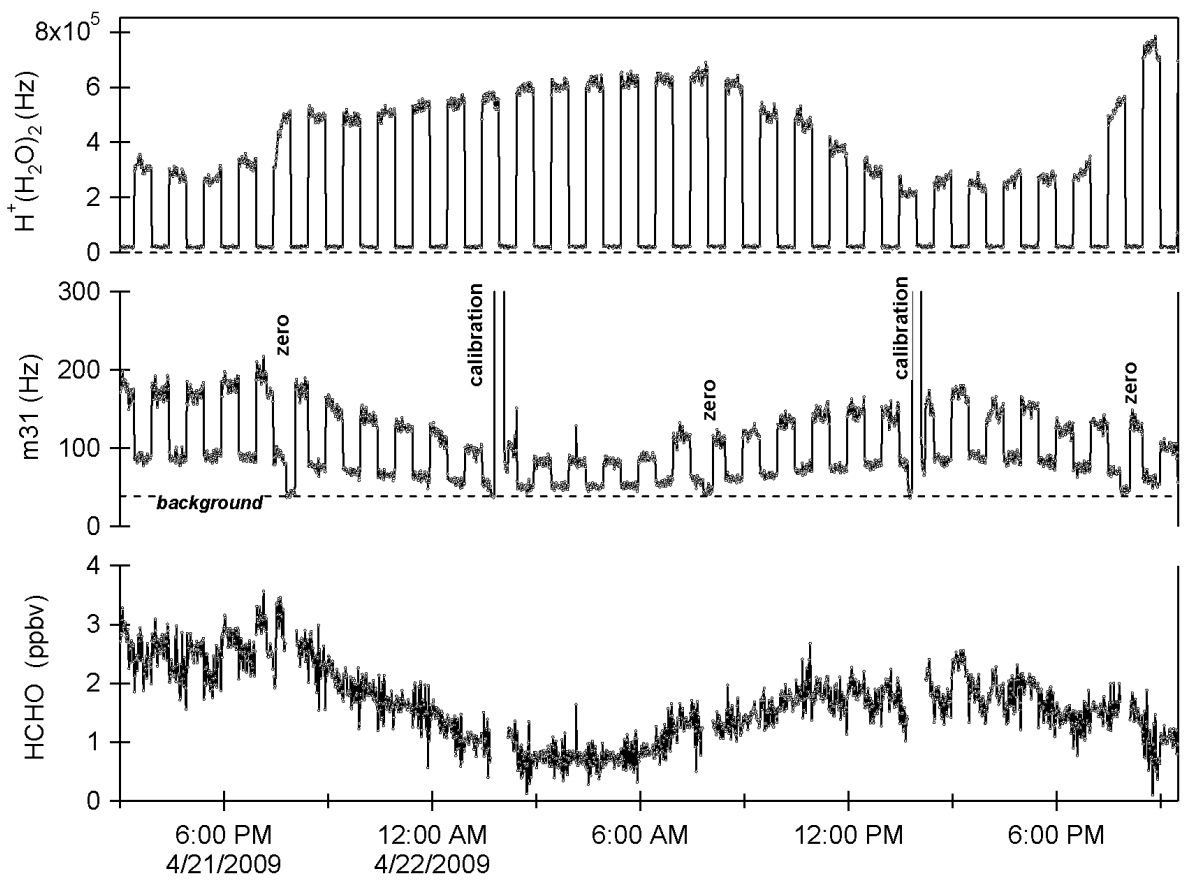

Fig. 7. Time series of $\mathrm{H}^{+}\left(\mathrm{H}_{2} \mathrm{O}\right)_{2}$ count rates in upper panel, HCHO count rates in middle panel (m31), and HCHO mixing ratios in lower panel. The crenulations in the $\mathrm{H}^{+}\left(\mathrm{H}_{2} \mathrm{O}\right)_{2}$ and $\mathrm{m} 31$ count rates are due to switching between ambient humidity sampling and dehumidified sampling conditions. Calibration and zero periods are indicated. HCHO mixing ratios were determined from the measured m31 count rates using separate calibration factors for the 2 sampling conditions.

figure that the worst discrepancy between $-30^{\circ} \mathrm{C}$ sampling and ambient humidity sampling occurred when the air was dry, as indicated by a crenulated pattern in the HCHO mixing ratio. $\mathrm{HCHO}$ normalized sensitivity displayed a strong dependence on water vapour at low water vapour concentrations and the dependence may not have been adequately captured by the calibration curve in Fig. 5 .

The reconstruction of the mixing ratio time series for several ions was complicated by significant differences in background count rates between dehumidified and ambient humidity sampling. The most notable differences were for $m / z=45$ (acetaldehyde) and $m / z=47$. In both instances, the dehumidified backgrounds were much higher, by factors of 2.0 and 4.2 , respectively. Contributions to the $m / z=45$ ion from $\mathrm{CO}_{2} \mathrm{H}^{+}$and at $m / z=47$ from the $\mathrm{N}_{2} \mathrm{H}_{3} \mathrm{O}^{+}$cluster ion have been noted (Hanson et al., 2009) as well as humidity dependent background count rates for $m / z=45$ (de Gouw and Warneke, 2007). Why more $\mathrm{N}_{2} \mathrm{H}_{3} \mathrm{O}^{+}$would form with less water vapour in the drift is somewhat puzzling, but suggests that it may be coming from the ion source rather than formed in the vacuum interface of the mass spectrometer.

Table 2 shows a significant increase in normalized sensitivity was achieved when the PTR-MS was operated at lower $E / N$ ratios. For the $100 \mathrm{Td}$ sampling period, the HCHO normalized sensitivity was $16.9 \mathrm{~Hz} / \mathrm{ppbv}$ and for the $80 \mathrm{Td}$ sampling period it was $25.0 \mathrm{~Hz} / \mathrm{ppbv}$. The $\mathrm{H}_{3} \mathrm{O}^{+}$count rates were $5.0 \times 10^{6} \mathrm{~Hz}$ for $100 \mathrm{Td}$ sampling and $4.6 \times 10^{6}$
$\mathrm{Hz}$ for $80 \mathrm{Td}$ sampling, resulting in absolute sensitivities of $84.5 \mathrm{~Hz} / \mathrm{ppbv}$ and $115 \mathrm{~Hz} / \mathrm{ppbv}$, respectively. The measured ion signal of $\mathrm{H}^{+}\left(\mathrm{H}_{2} \mathrm{O}\right)_{2}$ relative to $\mathrm{H}_{3} \mathrm{O}^{+}$was $4 \%$ at $100 \mathrm{Td}$ and $17 \%$ at $80 \mathrm{Td}$. Following the procedure described by de Gouw and Warneke (2007), the HCHO detection limit for the $100 \mathrm{Td}$ sampling period was calculated from the average $36 \mathrm{~Hz}$ background signal and $5 \mathrm{~s}$ dwell time to be $95 \mathrm{pptv}$. At $80 \mathrm{Td}$, the detection limit was calculated to be 78 pptv. Karl et al. (2003) reported formaldehyde detection limits $(S / N=2)$ of 1-2 ppbv using a PTR-MS operated at $123 \mathrm{Td}, 2.5 \mathrm{mbar}$ drift pressure and $4 \mathrm{MHz} \mathrm{H}_{3} \mathrm{O}^{+}$for a field study conducted in Houston during summer. Inomata et al. (2008) estimated a detection limit $(S / N=2)$ of $0.2-0.5$ ppbv depending on ambient humidity. Removing water vapour clearly improved the lower limit of formaldehyde detection by PTR-MS instruments. However, the detection limits calculated are based on detector noise and are not method detection limits that account for potential sampling losses of $\mathrm{HCHO}$ at low mixing ratios to the water trap and other tubing.

\subsection{Loss of compounds to water trap}

Loss of compounds to the water trap was evaluated for low vapour pressure compounds that would be expected to be lost to cold surfaces such as $\mathrm{C}_{3}$-alkylbenzenes and $\mathrm{C}_{4}$ alkylbenzenes. No losses were apparent during calibrations at 19.8 and $5 \mathrm{ppbv}$, respectively for 1,2,4-trimethylbenzene 


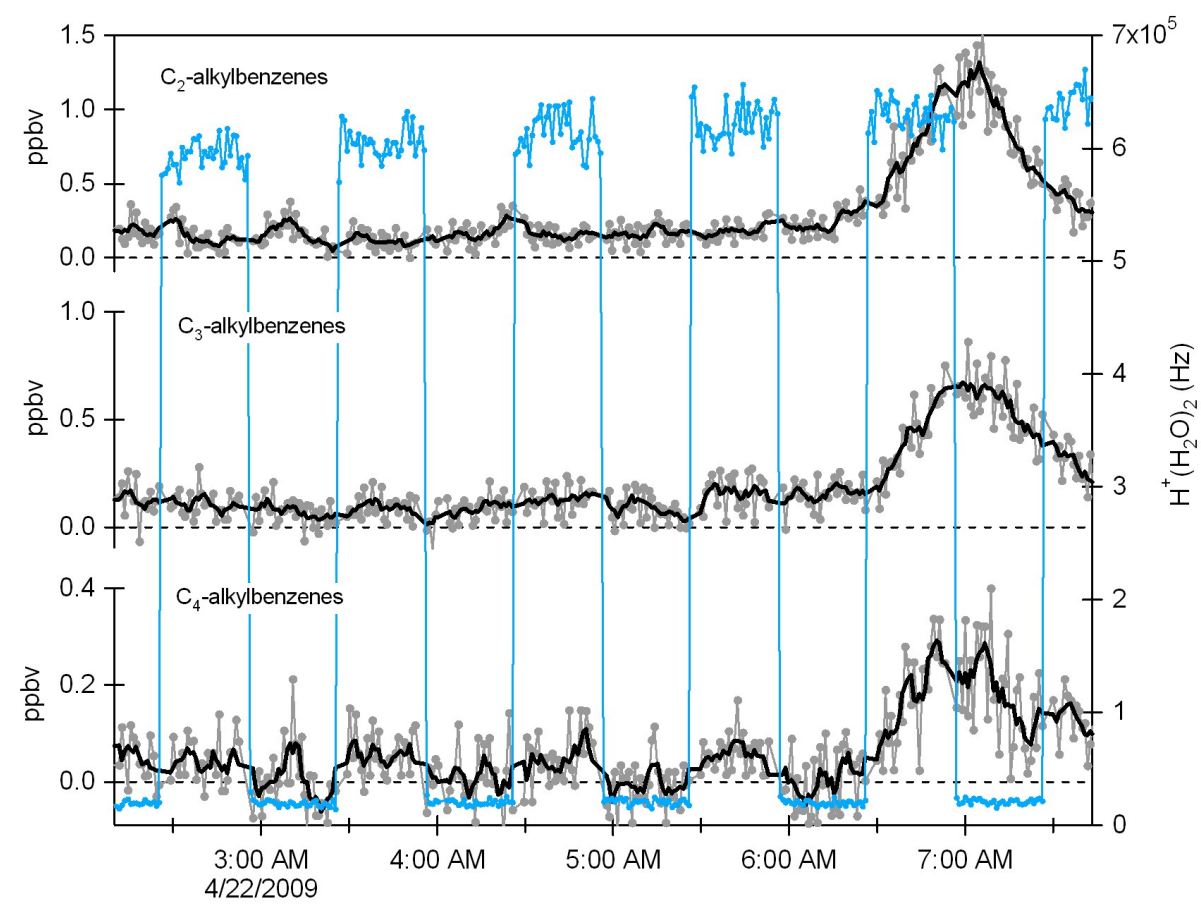

Fig. 8. Time series of alkylbenzene mixing ratios on left axes and $\mathrm{H}^{+}\left(\mathrm{H}_{2} \mathrm{O}\right)_{2}$ ion count rates (blue trace) on the right axis, illustrating loss of $\mathrm{C}_{4}$-alkylbenzenes through the water trap at low mixing ratios. Alkylbenzene data are given by grey circles. Solid black line through the data is a 5 point box smooth to better display trends.

and 1,2,3,5-tetramethylbenzene. The ambient data were also evaluated and a selected time series of $\mathrm{C}_{2}, \mathrm{C}_{3}$, and $\mathrm{C}_{4}$ alkylbenzenes mixing ratios is shown in Fig. 8. The clear square wave oscillation in the $\mathrm{H}^{+}\left(\mathrm{H}_{2} \mathrm{O}\right)_{2}$ ion signal indicates when the PTR-MS was sampling dehumidified air from the water trap at $-30^{\circ} \mathrm{C}$. The aromatics are a good test of water trap losses because their normalized sensitivity displayed a weak dependence on ambient humidity and there was no difference in their backgrounds between the 2 sampling conditions. No losses for $\mathrm{C}_{2}$ and $\mathrm{C}_{3}$-alkylbenzenes were observed in the data, as illustrated by the selected time series in Fig. 8. Losses of $\mathrm{C}_{4}$-alkylbenzenes to the water trap were evident at low mixing ratios $(<100 \mathrm{pptv})$, as indicated by ion signals that were not significantly different from background count rates when sampling through the water trap. The $\mathrm{C}_{4}$-alkylbenzenes were the only compounds from Table 1 that displayed any observable loss. We note that for the ions $m / z=47$ and $m / z=61$, attributed to formic and acetic acid, significant loss of ion signal was observed through the water trap.

\subsection{HCHO interferences}

Inomata et al. (2008) reported a positive interference on the formaldehyde ion due to methanol. This can be caused by the $\mathrm{O}_{2}^{+}+$methanol reaction to create an ion at $m / z=31$ $\left(\mathrm{CH}_{3} \mathrm{O}^{+}\right) . \mathrm{O}_{2}^{+}$is produced in the PTR-MS ion source and its presence can be controlled by adjusting water vapour flow rates through the source and extraction voltages into the drift. For the SHARP experiment $\mathrm{O}_{2}^{+}$ion signal was kept at $\sim 1.2 \%$ of $\mathrm{H}_{3} \mathrm{O}^{+}$ion signal. The level of the interference was established in the field by determining the $m / z=31$ ion signal during automated instrument calibrations from 14-16 April. During this period, the $\mathrm{HCHO}$ permeation tube was not yet integrated into the calibration system. The methanol calibration level was $19.8 \mathrm{ppbv}$. We found no significant difference in the normalized $m / z=31$ ion signal between the zero air period immediately before the calibration $(7.0 \pm 0.6 \mathrm{~Hz}$ per $\left.\mathrm{MHz} \mathrm{H}_{3} \mathrm{O}^{+}\right)$and the calibration period $(7.2 \pm 0.9 \mathrm{~Hz}$ per $\mathrm{MHz} \mathrm{H}_{3} \mathrm{O}^{+}$) for the seven zero-cal period pairs. The average difference (cal - zero) was $0.33 \pm 0.49 \mathrm{~Hz}$ per $\mathrm{MHz} \mathrm{H}_{3} \mathrm{O}^{+}$). We concluded that methanol interference was not significant for our HCHO data.

Another probable interference noted by Inomata et al. (2008) and Steinbacher et al. (2004) is methyl hydroperoxide $\left(\mathrm{CH}_{3} \mathrm{OOH}\right)$ which likely undergoes dissociative proton transfer reaction with $\mathrm{H}_{3} \mathrm{O}^{+}$to produce $\mathrm{CH}_{3} \mathrm{O}^{+}$ions. Inomata et al. (2008) reported significant fragmentation of $\mathrm{CH}_{3} \mathrm{OOH}$ producing $m / z=31$ and $m / z=49$ ion signals. In our experience with our instrument operating at $120 \mathrm{Td}$, there is no significant ion signal at $m / z=49$, the $\mathrm{CH}_{3} \mathrm{OOHH}^{+}$ion. For the SHARP field experiment, the drift field intensity was reduced during the month of May to $100 \mathrm{Td}$, and then to $80 \mathrm{Td}$ for the last week of May. Under these conditions a significant 


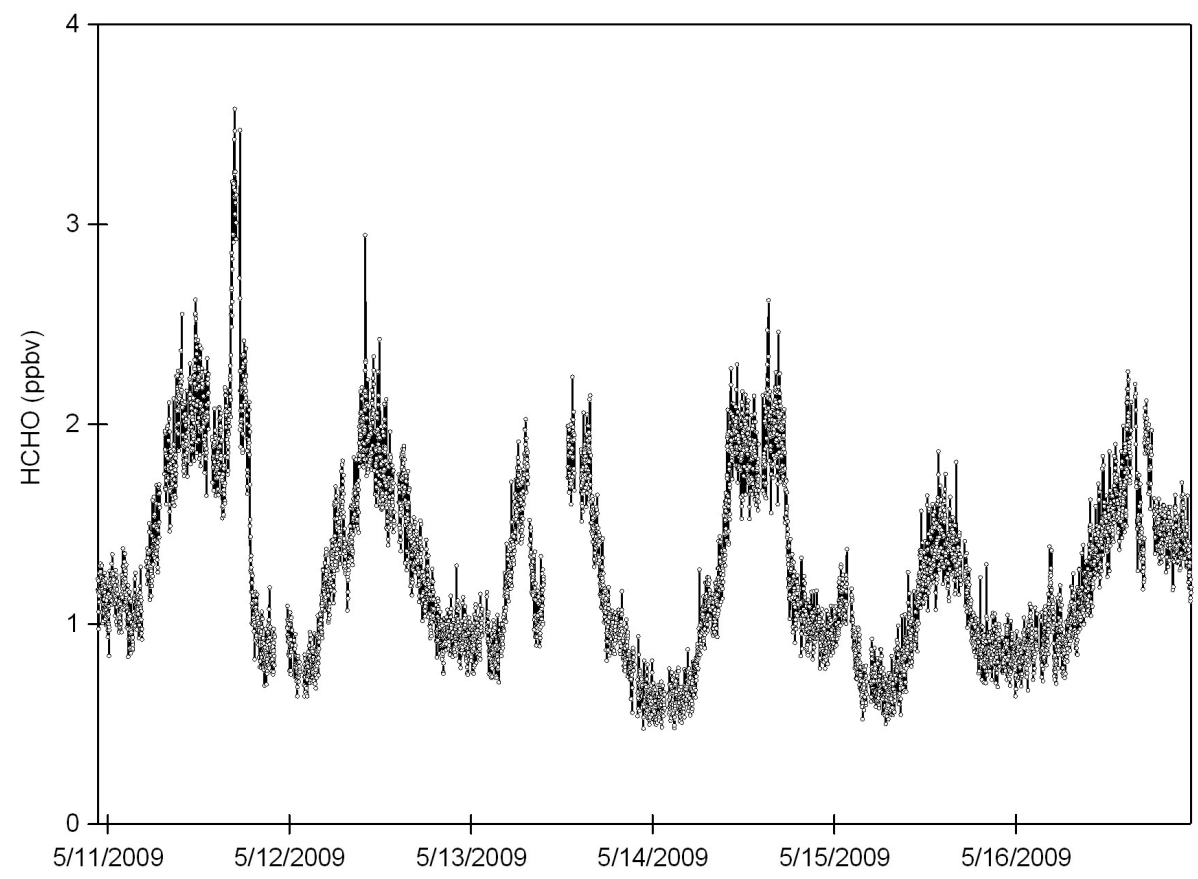

Fig. 9. Formaldehyde data illustrating signal-to-noise compared to amplitude of diel variation. There is a data point every $73 \mathrm{~s}$ and the formaldehyde dwell time was $5 \mathrm{~s}$. The sample was dried to $-30{ }^{\circ} \mathrm{C}$ dew point and the PTR-MS operated at $100 \mathrm{Td}$ and a pressure of 2.1 mbar.

ion signal at $m / z=49$ was observed. A small fraction of this ion signal was due to the protonated formaldehyde water cluster ion. The estimated interference was $0.09 \mathrm{~Hz}$ per ppbv of formaldehyde at $100 \mathrm{Td}$. Assuming $\mathrm{CH}_{3} \mathrm{OOH}$ has a similar normalized sensitivity as methanol, this would amount to only $\sim 8$ pptv $\mathrm{CH}_{3} \mathrm{OOH}$ per ppbv of formaldehyde. It seems possible that operating the PTR-MS at lower field intensities would reduce interferences from $\mathrm{CH}_{3} \mathrm{OOH}$ and allow $\mathrm{CH}_{3} \mathrm{OOH}$ to be measured. The level of interference from $\mathrm{CH}_{3} \mathrm{OOH}$ on the $m / z=31$ ion signal could not be quantified in the field study. This issue will be the subject of a future study.

\subsection{Dehumidifed field sampling}

Figure 9 shows a time series plot for a 2 day period for the $100 \mathrm{Td}$ operating condition to illustrate the signal-tonoise of the HCHO data. Clear diel variations with amplitude of $\sim 1$ ppbv could be observed with nighttime/early morning minima and maxima during the day. During this time, air flow was from the south and relatively unpolluted. Clear diel variations in isoprene $(m / z=69)$ and its photoproducts methacrolein and methyl vinyl ketone $(\mathrm{m} / \mathrm{z}=71)$ were observed so a likely mechanism of diel HCHO variation was in its production rates from isoprene oxidation (Sumner et al., 2001). Lowest observed HCHO mixing ratios were 480 pptv, well above the calculated detection limits. The minimum mixing ratios were consistent with minimums reported for
Houston (Wert et al., 2003; Karl et al., 2003; Dasgupta et al., 2005; Eom et al., 2008). A small plume of HCHO was observed on 11 May that may indicate industrial emissions. A separate analysis of the HCHO and VOC data collected in this study will be presented elsewhere.

Figure 10 illustrates the correspondence between HCHO mixing ratios and the ion signal at $m / z=49$ which we interpret as $\mathrm{CH}_{3} \mathrm{OOH}$. The figure displays $5 \mathrm{~min}$ average data. Mixing ratios of $\mathrm{CH}_{3} \mathrm{OOH}$ were determined assuming it had the same normalized sensitivity as methanol. This is an assumption made only to evaluate the temporal behaviour and potential merit of $\mathrm{CH}_{3} \mathrm{OOH}$ determination by PTR-MS instruments. $\mathrm{CH}_{3} \mathrm{OOH}$ displayed a diel cycle similar to that of $\mathrm{HCHO}$. The $\mathrm{CH}_{3} \mathrm{OOH}$ maxima were sometimes displaced later in the afternoon, reflecting perhaps lower NO concentrations and, hence, greater production rates of $\mathrm{CH}_{3} \mathrm{OOH}$ from the $\mathrm{CH}_{3} \mathrm{OO}+\mathrm{HO}_{2}$ reaction. On 17 May, a cold front passed through bringing rainy weather and a change in wind direction from a relatively clean southerly flow to polluted north easterly flow impacted by the heavily industrialized area known as the Houston Ship Channel. $\mathrm{CH}_{3} \mathrm{OOH}$ decreased by a factor of 3 during the cold front passage and remained relatively low during the period of polluted northeasterly flow, whereas HCHO mixing ratios were much higher. Plumes of $\mathrm{HCHO}$ were observed during this period with the highest mixing ratio of $11.2 \mathrm{ppbv}$. The $m / z=49$ ion signal data are interesting and suggest the behaviour of peroxide product. This warrants further investigation to determine 


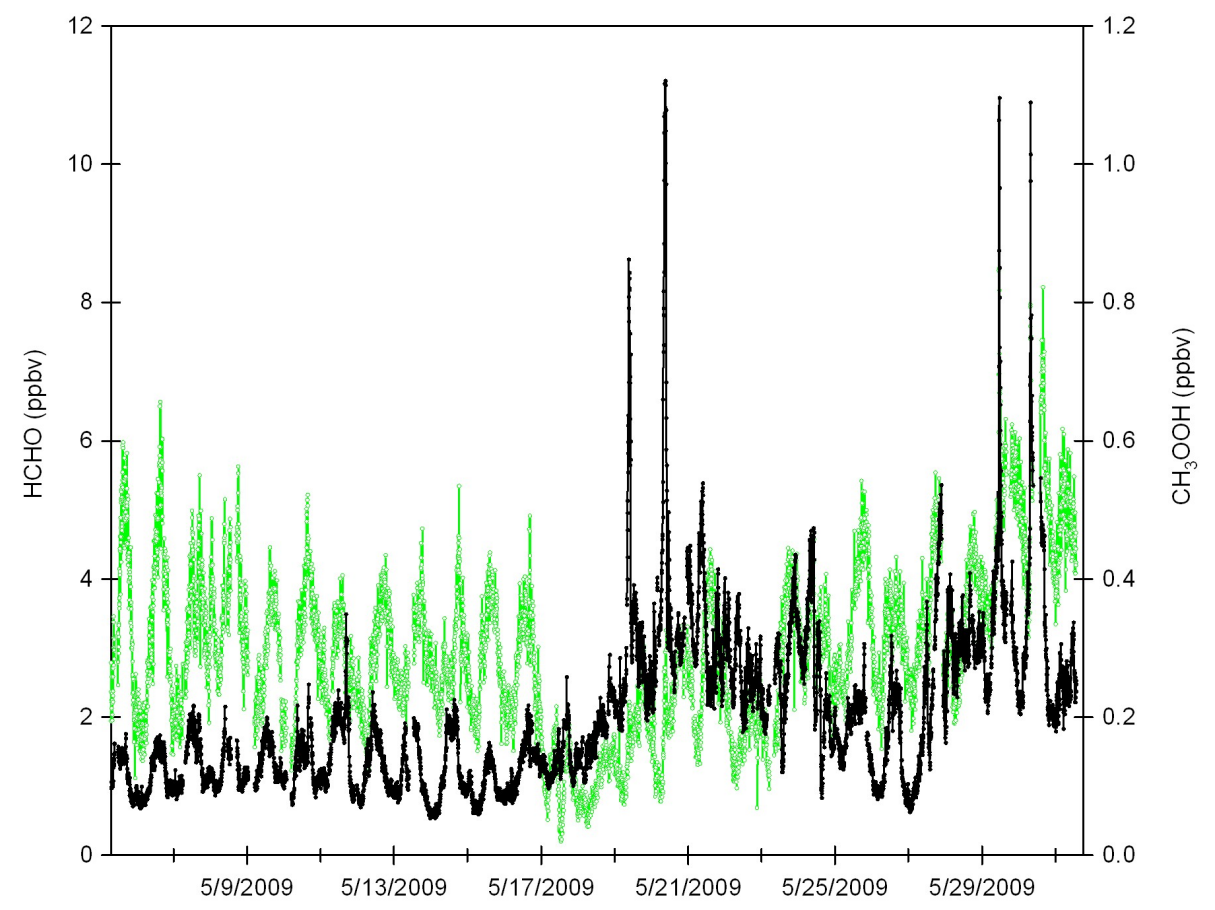

Fig. 10. Time series of $5 \mathrm{~min}$ averages for $\mathrm{HCHO}$ (black) and the $m / z=49$ ion signal interpreted to be $\mathrm{CH}_{3} \mathrm{OOH}$ (green). Both species displayed a clear diel variation with nighttime minimums during a period with persistent southern air flow (5 May-17 May). The decrease in $\mathrm{CH}_{3} \mathrm{OOH}$ on 17 May corresponds to the passage of a cold front and rainy weather. The cold front passage also marked a change in air flow from southerly to northeasterly, bringing polluted air from a heavily industrialized region of Houston and higher HCHO mixing ratios.

$\mathrm{CH}_{3} \mathrm{OOH}$ transmission efficiency through the water trap and the degree of fragmentation upon reaction with $\mathrm{H}_{3} \mathrm{O}^{+}$as a function of $E / N$.

\section{Conclusions}

The humidity dependence of the normalized sensitivity $\left(\mathrm{Hz} / \mathrm{ppbv}\right.$ per $\left.\mathrm{MHz}_{3} \mathrm{O}^{+}\right)$for formaldehyde and other VOC was investigated in both laboratory experiments and in a field study. Formaldehyde normalized sensitivity displayed an exponential dependence on water vapour concentration. Benzene displayed a weak positive dependence. In field tests, a factor of 7 increase in formaldehyde normalized sensitivity was demonstrated by drying the air sample to a dew point of $-30^{\circ} \mathrm{C}$. Laboratory tests showed that at temperatures warmer than $-30^{\circ} \mathrm{C}$ there was significant uptake of formaldehyde and other soluble organics to the ice surface, consistent with the presence of a liquid water layer on the ice surface. Benzene, toluene, $\mathrm{C}_{2}$-alkylbenzenes, and $\mathrm{C}_{3}$-alkylbenzenes passed quantitatively through the trap at $-30^{\circ} \mathrm{C}$. Evidence of $\mathrm{C}_{4}$-alkylbenzene losses were observed at mixing ratios less than $100 \mathrm{pptv}$. Drying the sample has four benefits: (1) elimination of water vapour dependent sensitivity for all species; (2) significant increase in $\mathrm{HCHO}$ normalized sensitivity (3) ability to operate drift tube at low $E / N$ ratios to further increase sensitivity and reduce dissociative proton transfer reactions, and (4) reduced clustering due to low water vapour in the drift tube. Field testing at an $E / N$ ratio of $100 \mathrm{Td}$ demonstrated that $1 \mathrm{ppbv}$ diel variation in HCHO mixing ratios could be easily resolved. Detection limits at $100 \mathrm{Td}$ were calculated to be $95 \mathrm{pptv}$, and $78 \mathrm{pptv}$ at an $E / N$ ratio of $80 \mathrm{Td}$. The formaldehyde normalized sensitivity at $80 \mathrm{Td}$ was $25 \mathrm{~Hz} / \mathrm{ppbv}$, yielding an absolute sensitivity of $115 \mathrm{~Hz} /$ ppbv. During field testing, a significant ion signal at $m / z=49$ was observed which was attributed to $\mathrm{CH}_{3} \mathrm{OOH}$. This species is potentially quantifiable by PTRMS instruments if they are operated at low $E / N$ and low water vapour concentrations and warrants further investigation.

Acknowledgements. This work was funded by the Houston Advanced Research Center (HARC). The authors would like to thank colleagues at the University of Houston for organizing the SHARP field campaign.

Edited by: J. Williams

\section{References}

Dash, J. G., Fu, H., and Wettlaufer, J. S.: The premelting of ice and its environmental consequences, Rep. Prog. Phys., 58, 115-167, 1995.

de Gouw, J. and Warneke, C.: Measurement of volatile organic compounds in the Earth's atmosphere using proton transfer reaction mass spectrometry, Mass Spectrom. Rev., 26, 223-257, 2007. 
Dasgupta, P. K., Li, J., Zhang, G., Luke, W. T., Mcclenny, W. A., Stutz, J., and Freid, A.: Summertime ambient formaldehyde in five US metropolitan areas: Nashville, Atlanta, Houston, Philadelphia, and Tampa, Environ. Sci. Technol., 39, 4767-4783, 2005.

Eom, I.-Y., Li, Q., Li, J., and Dasgupta, P. K.: Robust hybrid flow analyzer for formaldehyde, Environ. Sci. Technol., 42, 12211226, 2008

Fernandez, M. T., Williams, C., Mason, R. S., and Cabral, B. J. C.: Experimental and theoretical proton affinity of limonene, J. Chem. Soc. Faraday Trans., 94, 1427-1430, 1998.

Goebbert, D. J. and Wenthold, P. G.: Water dimer proton affinity from the kinetic method: dissociation energy of the water dimer, Eur. J. Mass Spectrom., 10, 837-845, 2004.

Goldan, P. D., Kuster, W. C., Fehsenfeld, F. C., and Montzka, S. A.: Hydrocarbon measurements in the southeastern United States, The Rural Oxidants in Southern Environments (ROSE) Program 1990, J. Geophys. Res., 100, 25945-25963, 1995.

Hansel, A., Jordan, A. , Holzinger, R., Prazeller, P., Vogel, W., and Lindinger, W.: Proton transfer reaction mass spectrometry: online trace gas analysis at the ppb level, Int. J. Mass Spectrom., 149/150, 609-619, 1995.

Hansel, A., Singer, W., Wisthaler, A., Schwarzman, M., and Lindinger, W.: Energy dependencies of the proton transfer reactions $\mathrm{H}_{3} \mathrm{O}^{+}+\mathrm{CH}_{2} \mathrm{O} \leftrightarrow \mathrm{CH}_{2} \mathrm{OH}^{+}+\mathrm{H}_{2} \mathrm{O}$, Int. J. Mass Spectrom., 167/168, 697-703, 1997.

Hanson, D. R., Koppes, M., Stoffers, A., Harsdorf, R., and Edelen, K.: Proton transfer mass spectrometry at $11 \mathrm{hPa}$ with a circular glow discharge: sensitivities and applications, Int. J. Mass Spectrom., 282, 28-37, 2009.

Holzinger, R., Warneke, C., Hansel, A., Jordan, A., and Lindinger, W.: Biomass burning as a source of formaldehyde, acetaldehyde, methanol, acetone, acetonitrile, and hydrogen cyanide, Geophys. Res. Lett., 26, 1161-1164. 1999.

Hunter, E. P. and Lias, S. G.: Evaluated gas phase basicities and proton affinities of molecules: An update, J. Phys. Chem. Ref. Data, 27(3), 413-656, 1998.

Inomata, S., Tanimoto, H., Kameyama, S., Tsunogai, U., Irie, H., Kanaya, Y., and Wang, Z.: Technical Note: Determination of formaldehyde mixing ratios in air with PTR-MS: laboratory experiments and field measurements, Atmos. Chem. Phys., 8, 273284,2008 http://www.atmos-chem-phys.net/8/273/2008/.

Karl, T., Jobson, T., Kuster, W. C., Williams, E., Stutz, J., Shetter, R., Hall, S. R., Goldan, P., Fehsenfeld, F., and Lindinger, W.: Use of proton-transfer-reaction mass spectrometry to characterize volatile organic compound sources at the La Porte super site during the Texas Air Quality Study 2000, J. Geophys. Res., 108(D16), 4508, doi:10.1029/2002JD003333, 2003.

Karl, T. G., Christian, T. J., Yokelson, R. J., Artaxo, P., Hao, W. M., and Guenther, A.: The Tropical Forest and Fire Emissions Experiment: method evaluation of volatile organic compound emissions measured by PTR-MS, FTIR, and GC from tropical biomass burning, Atmos. Chem. Phys., 7, 5883-5897, 2007, http://www.atmos-chem-phys.net/7/5883/2007/.
Lindinger, W., Hansel, A., and Jordan, A.: On-line monitoring of volatile organic compounds at pptv levels by means of ProtonTransfer-Reaction Mass Spectrometry (PTR-MS) Medical applications, food control and environmental research, Int. J. Mass. Spectrom., 173, 191-241, 1998.

Midey, A. J., Arnold, S. T., and Viggiano, A. A.: Reactions of $\mathrm{H}_{3} \mathrm{O}^{+}\left(\mathrm{H}_{2} \mathrm{O}\right)_{n}$ with formaldehyde and acetaldehyde, J. Phys. Chem. A, 104, 2706-2709, 2000.

Midey, A. J., Williams, S., Arnold, S. T., and Viggiano, A. A.: Reactions of $\mathrm{H}_{3} \mathrm{O}^{+}\left(\mathrm{H}_{2} \mathrm{O}\right)_{0,1}$ with alkylbenzenes from 298 to $1200 \mathrm{~K}$, J. Phys. Chem. A, 106, 11726-11738, 2002.

Seco, R., Penuelas, J., and Filella, I.: Formaldehyde emission and uptake by Mediterranean trees Quercus ilex and Pinus halepensis, Atmos. Environ. 42, 7907-7914, 2008.

Spanel, P. and Smith, D.: Reactions of hydrated hydronium ions and hydrated hydroxide ions with some hydrocarbons and oxygenbearing organic molecules, J. Phys. Chem., 99, 15551-15556, 1995.

Solouki, T. and Szulejko, J. E.: Bimolecular and unimolecular contributions to the disparate self-chemical ionizations of alphapinene and camphene isomers, J. Am. Soc. Mass Spectrom., 18, 2026-2039, 2007.

Staudinger, J. and Roberts, P. V.: A critical review of Henry's law constants for environmental applications, Crit. Rev. Env. Sci. Tec., 26, 205-297, 1996.

Steinbacher, M., Dommen, J., Ammann, C., Spirig, C., Neftel, A., and Prevot, A. S. H.: Performance characteristics of a protontransfer-reaction mass spectrometer (PTR-MS) derived from laboratory and field measurements, Int. J. Mass Spectrom., 239, 117-128. 2004.

$\mathrm{Su}, \mathrm{T}$. and Chesnavich, W. J.: Parameterization of the ion-molecule collision rate constant by trajectory calculations, J. Chem. Phys., 76, 5183-5185, 1982.

$\mathrm{Su}, \mathrm{T} .:$ Erratum: Trajectory calculations of ion-polar molecule capture rate constants at low temperatures, J. Chem. Phys., 89, 5355, 1988.

Sumner, A. L., Shepson, P. B., and Couch, T. L.: A study of formaldehyde chemistry above a forest canopy, J. Geophys. Res., 106, 24387-24405, 2001.

Taipale, R., Ruuskanen, T. M., Rinne, J., Kajos, M. K., Hakola, H., Pohja, T., and Kulmala, M.: Technical Note: Quantitative long-term measurements of VOC concentrations by PTR-MS measurement, calibration, and volume mixing ratio calculation methods, Atmos. Chem. Phys., 8, 6681-6698, 2008, http://www.atmos-chem-phys.net/8/6681/2008/.

Warneke, C., van der Veen, C., Luxembourge, S., de Gouw, J. A., and Kok, A.: Measurements of benzene and toluene in ambient air using proton-transfer-reaction mass spectrometry: calibration, humidity dependence, and field intercomparison, Int. J. Mass Spectrom., 207, 167-182, 2001.

Wert, B. P., Trainer, M., and Fried, A.: Signatures of terminal alkene oxidation in airborne formaldehyde measurements during TexAQS 2000, J. Geophys. Res., 108, 4104, doi:10.1029/2002JD002502, 2003.

Zhao, J. and Zhang, R.: Proton transfer reaction rate constants between hydronium ion $\left(\mathrm{H}_{3} \mathrm{O}^{+}\right)$and volatile organic compounds, Atmos. Environ., 38, 2177-2185. 2004. 